\title{
On the Maximum Bandwidth Attainable by Power Factor Correctors with a Standard Compensator
}

Javier Sebastián (Member, IEEE), Diego G. Lamar (Member, IEEE), Alberto Rodríguez (Student Member, IEEE), Manuel Arias (Student Member, IEEE) and Arturo Fernández (Member, IEEE).

Universidad de Oviedo. Grupo de Sistemas Electrónicos de Alimentación (SEA)

Edificio Departamental n 3. Campus Universitario de Viesques. 33204 Gijón. SPAIN E-mail: sebas@uniovi.es

Abstract- When a Power Factor Corrector (PFC) is designed with a relatively fast output-voltage feedback loop, the static and the dynamic behaviour of the power stage is different to that obtained with a slow output-voltage feedback loop. This is because of the influence of the voltage ripple that is present on the control signal. This voltage ripple generates a "parasitic" feedback loop, which is different to the "desired" one (the dc output-voltage feedback loop). The effect of this "parasitic" feedback loop can be integrated into the power stage model in such a way that a new model for the power stage is obtained. Assuming this model, the only feedback loop is the one corresponding to the dc output voltage, i.e., the “desired" output-voltage feedback loop. The design of this feedback loop determines the final dynamic behaviour of the PFC, which can be optimized to achieve the maximum bandwidth compatible with compliance with existing regulations regarding the injection of line harmonics and PFC stability. The main objective of this paper is thus to determine the maximum crossover angular frequency, $\omega_{0}$, compatible with a desired value of the phase margin, $\phi_{\mathrm{m}}$, and which complies with EN 61000-3-2 regulations in all possible classes of equipment (A, B, C and D) when a standard compensator (a PI with one additional pole) is used. The results obtained show that the maximum bandwidth attainable by a PFC strongly depends on its Class. This maximum bandwidth depends on the power processed by the converter in the case of equipment classified as Class A or Class B. However, the maximum bandwidth attainable for equipment belonging to Class C or to Class D does not depend on the power processed and is always higher in the case of Class D than in that of Class C. 


\section{On the Maximum Bandwidth Attainable by Power Factor Correctors with a Standard Compensator}

Abstract- When a Power Factor Corrector (PFC) is designed with a relatively fast output-voltage feedback loop, the static and the dynamic behaviour of the power stage is different to that obtained with a slow output-voltage feedback loop. This is because of the influence of the voltage ripple that is present on the control signal. This voltage ripple generates a "parasitic" feedback loop, which is different to the "desired" one (the dc output-voltage feedback loop). The effect of this "parasitic" feedback loop can be integrated into the power stage model in such a way that a new model for the power stage is obtained. Assuming this model, the only feedback loop is the one corresponding to the dc output voltage, i.e., the “desired” output-voltage feedback loop. The design of this feedback loop determines the final dynamic behaviour of the PFC, which can be optimized to achieve the maximum bandwidth compatible with compliance with existing regulations regarding the injection of line harmonics and PFC stability. The main objective of this paper is thus to determine the maximum crossover angular frequency, $\omega_{0}$, compatible with a desired value of the phase margin, $\phi_{\mathrm{m}}$, and which complies with EN 61000-3-2 regulations in all possible classes of equipment (A, B, C and D) when a standard compensator (a PI with one additional pole) is used. The results obtained show that the maximum bandwidth attainable by a PFC strongly depends on its Class. This maximum bandwidth depends on the power processed by the converter in the case of equipment classified as Class A or Class B. However, the maximum bandwidth attainable for equipment belonging to Class $\mathrm{C}$ or to Class D does not depend on the power processed and is always higher in the case of Class D than in that of Class C.

\section{INTRODUCTION}

Figure 1.a shows the general scheme of an active Power Factor Corrector (PFC) controlled by an analog multiplier, which is the most widely-used circuitry to control converters of this type. The standard design of the output-voltage feedback loop shown in this figure implies low ripple on the control signal, $\mathrm{v}_{\mathrm{A}}$, to avoid line current distortion $[1,2]$. However, this design causes low bandwidth in the output-voltage feedback loop, which limits the transient response of the PFC [2, 3]. To achieve a faster transient response, the bandwidth of the voltage-loop compensator, $A_{R}$, must be relatively high $[2,3]$; consequently, considerable voltage ripple appears on the control signal, $\mathrm{v}_{\mathrm{A}}$ (Fig. 1.b). Although some solutions have been proposed to cancel this voltage ripple while conserving a fast response [3-11], their implementations are not easy in the case of low-cost PFCs. Thus, the easiest way to achieve a fast response is to allow the aforementioned ripple to be present on $\mathrm{v}_{\mathrm{A}}$ [12] by using a standard compensator (such as the one shown in Fig. 1c) designed to have a relatively wide bandwidth. 


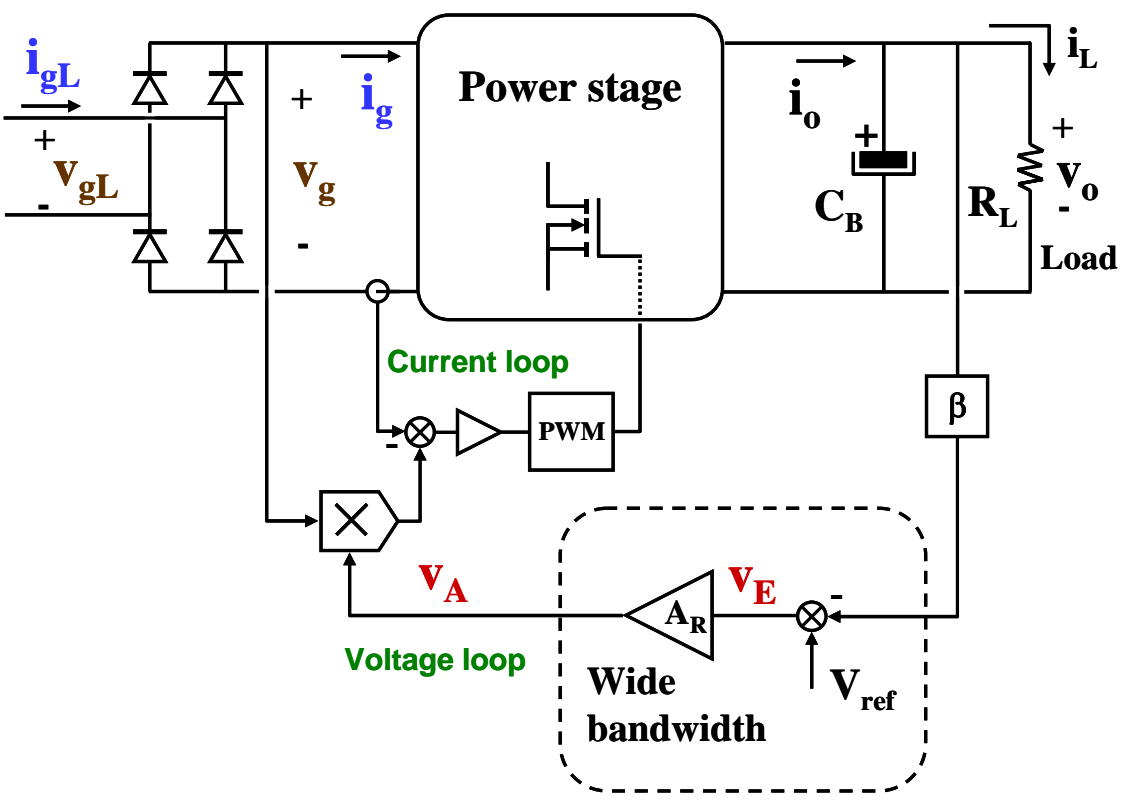

Error amplifier circuitry

(a)

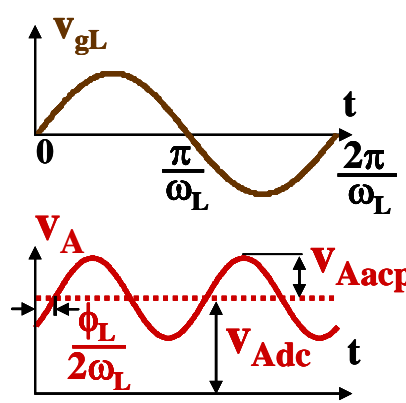

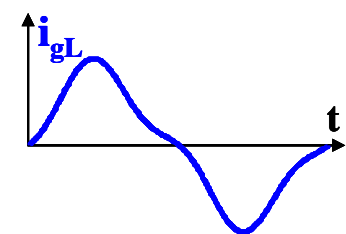

(b)

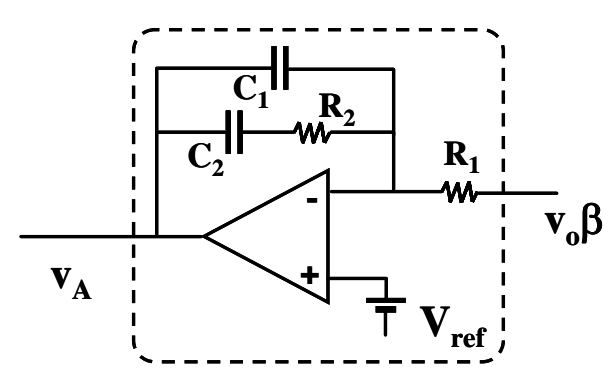

Error amplifier circuitry

(c)

Fig. 1: a) PFC with a wide bandwidth compensator in the output-voltage feedback loop. b) Main waveforms. c) Implementation of the error amplifier circuitry (voltage subtraction, error amplification and compensation network).

As given in [12], the line current distortion due to the voltage ripple on $\mathrm{v}_{\mathrm{A}}$ has a limited effect on the compliance with EN 61000-3-2 regulations. It should be noted that these regulations only impose the condition that the harmonic content of the line current must be lower than the limits imposed by them. As a consequence of this, many authors have introduced PFC topologies with non-sinusoidal (but with limited harmonics) line current waveforms [13-20].

With an appreciable ripple on the control voltage $\mathrm{v}_{\mathrm{A}}$, both the static [21] and dynamic [22] behaviour of the PFC vary in relation to that corresponding to design $A_{R}$ with low-bandwidth. An average small-signal model was developed in [22] to study this dynamic behaviour. Taking into account this model, the main objective of the present paper is to determine the maximum 
bandwidth that a PFC with a standard compensator can attain. This maximum bandwidth must be compatible with two very important requirements of any PFC:

- The PFC must comply with EN 61000-3-2 regulations [23, 24].

- The PFC must be stable and its phase margin must be reasonable (e.g., greater than $45^{\circ}$ ).

\section{ReViewing the Static and Dynamic Behaviour of PFCs with an Appreciable Ripple in the OutPut-Voltage}

\section{FEEDBACK LOOP}

The voltage and the current at the input of the power stage shown in Fig. 1 can be written as follows:

$$
\begin{aligned}
& v_{g}\left(\omega_{L} t\right)=v_{g p}\left|\sin \left(\omega_{L} t\right)\right|, \\
& i_{g}\left(\omega_{L} t\right)=\frac{v_{g p}\left|\sin \left(\omega_{L} t\right)\right| v_{A}(t)}{K_{M}},
\end{aligned}
$$

where $v_{g p}$ is the peak value of $v_{g}\left(\omega_{L} t\right), \omega_{L}$ is the line angular frequency, $K_{M}$ is a constant determined by the controller and $v_{A}(t)$ is the voltage at the compensator output. This voltage can be rewritten as follows:

$$
\begin{aligned}
& \mathrm{v}_{\mathrm{A}}(\mathrm{t})=\mathrm{v}_{\text {Adc }}+\mathrm{v}_{\text {Aac }}(\mathrm{t}), \\
& \mathrm{v}_{\text {Aac }}(\mathrm{t})=\mathrm{v}_{\text {Aacp }} \sin \left(2 \omega_{\mathrm{L}} \mathrm{t}-\phi_{\mathrm{L}}\right),
\end{aligned}
$$

where $\mathrm{v}_{\mathrm{Adc}}$ is the dc component of $\mathrm{v}_{\mathrm{A}}(\mathrm{t}), \mathrm{v}_{\mathrm{Aac}}(\mathrm{t})$ is its ac component, $\mathrm{v}_{\text {Aacp }}$ is the amplitude of $\mathrm{v}_{\text {Aac }}(\mathrm{t})$ and $\phi_{\mathrm{L}}$ is its phase lag angle as given in Fig. 1.b (i.e., the delay time between the zero crossing of the line voltage and the zero crossing of the ripple on $\mathrm{v}_{\mathrm{A}}$ is $\left.\phi_{\mathrm{L}} / 2 \omega_{\mathrm{L}}\right)$. Note that only a component of twice the line frequency has been considered as the ac component of $\mathrm{v}_{\mathrm{A}}(\mathrm{t})$. This is because the only significant harmonic in the voltage ripple across the bulk capacitor $\mathrm{C}_{\mathrm{B}}$ is the one of twice the line frequency (second harmonic), the remaining harmonics having been considerably filtered by this capacitor [21].

The relative value of the voltage ripple on $v_{A}(t)$ is defined as follows:

$$
\mathrm{k}=\frac{\mathrm{v}_{\text {Aacp }}}{\mathrm{v}_{\text {Adc }}} .
$$


Therefore the voltage ripple can be defined by means of only two parameters: its amplitude, $\mathrm{v}_{\text {Aacp }}$, and its phase lag angle, $\phi_{\mathrm{L}}$. As the voltage ripple amplitude can be related to $\mathrm{v}_{\mathrm{Adc}}$ through $\mathrm{k}(5)$, then $\mathrm{v}_{\mathrm{Adc}}, \mathrm{k}$ and $\phi_{\mathrm{L}}$ fully define the normalized state of the control variable $\mathrm{v}_{\mathrm{A}}(\mathrm{t})$.

As a consequence of having voltage ripple on the control signal, $\mathrm{v}_{\mathrm{A}}(\mathrm{t})$, all the static [21] and dynamic [22] electrical quantities of the PFC vary in relation to those corresponding to the standard design case [25], i.e., with a control signal with no ripple. In fact, the control signal $\mathrm{v}_{\mathrm{A}}(\mathrm{t})$ is defined by three quantities:

- One "desired" control variable, $\mathrm{v}_{\mathrm{Adc}}$, which is the only existing control variable in standard designs (with a control signal with no ripple, [25]).

- Two "parasitic" control variables, $\mathrm{v}_{\text {Aacp }}$ and $\phi_{\mathrm{L}}$, which define the voltage ripple on $\mathrm{v}_{\mathrm{A}}(\mathrm{t})$.

The "desired" control variable determines a "desired" feedback loop, whereas the "parasitic" control variables determine a "parasitic" feedback loop with two different branches (see Fig. 2) corresponding to the amplitude of the voltage ripple, $\mathrm{v}_{\text {Aacp }}$, and its phase lag angle, $\phi_{\mathrm{L}}$. As the parasitic feedback loop corresponds to the voltage component with twice the line frequency, the gain of the compensator $A_{R}$ at $2 \omega_{L}$ determines the values of $v_{A a c p}$ and $\phi_{\mathrm{L}}$ through $A_{R 2 \omega L}$ and $\phi_{\mathrm{R} 2 \omega \mathrm{L}}$, which are the magnitude and the phase lag angle, respectively, of $A_{R}$ at twice the line frequency.

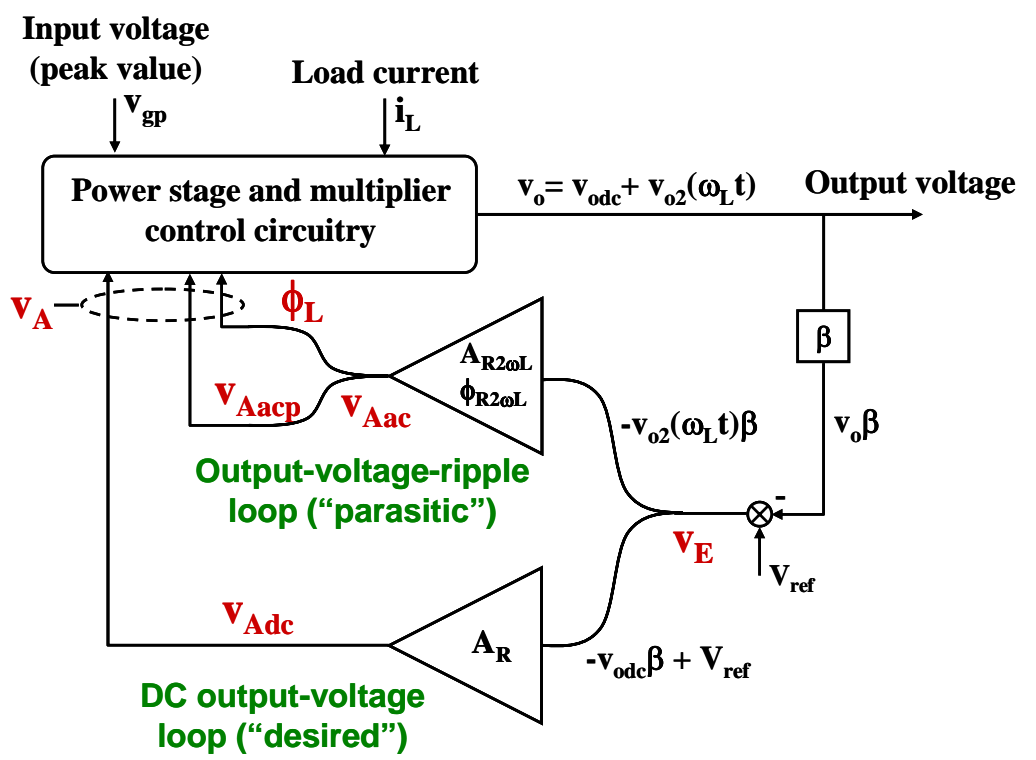

Fig. 2: Block diagram of the circuit shown in Fig. 1.a. 
Another important consequence of having voltage ripple on $v_{A}(t)$ is that the current injected by the power stage into the $C_{B}-R_{L}$ cell ( $i_{o}$ in Fig. 1.a) is also different in this case. From [21], the dc component of $i_{o}$ is:

$$
\mathrm{i}_{\mathrm{odc}}=\frac{\mathrm{v}_{\mathrm{o}}}{\mathrm{R}_{\mathrm{L}}}=\frac{\mathrm{v}_{\mathrm{gp}}^{2} \mathrm{v}_{\text {Adc }}}{4 \mathrm{~K}_{\mathrm{M}} \mathrm{v}_{\mathrm{o}}}\left(2+\frac{\mathrm{v}_{\text {Aacp }}}{\mathrm{v}_{\text {Adc }}} \sin \phi_{\mathrm{L}}\right)
$$

whereas the component of twice the line frequency has an amplitude:

$$
\mathrm{i}_{\mathrm{o} 2 \mathrm{p}}=\frac{2 \mathrm{v}_{\mathrm{o}}}{\mathrm{R}_{\mathrm{L}}} \cdot \frac{\sqrt{1+\mathrm{k}^{2}+2 \mathrm{k} \sin \phi_{\mathrm{L}}}}{2+\mathrm{k} \sin \phi_{\mathrm{L}}}=\frac{\mathrm{v}_{\mathrm{gp}}^{2}}{2 \mathrm{~K}_{\mathrm{M}} \mathrm{v}_{\mathrm{o}}} \sqrt{\mathrm{v}_{\mathrm{Adc}}^{2}+\mathrm{v}_{\mathrm{Aacp}}^{2}+2 \mathrm{v}_{\mathrm{Adc}} \mathrm{v}_{\text {Aacp }} \sin \phi_{\mathrm{L}}} \text {, }
$$

and a phase lag angle:

$$
\phi_{\text {io } 2}=\arctan \frac{1+\mathrm{k} \sin \phi_{\mathrm{L}}}{\mathrm{k} \cos \phi_{\mathrm{L}}}=\arctan \frac{\mathrm{v}_{\mathrm{Adc}}+\mathrm{v}_{\text {Aacp }} \sin \phi_{\mathrm{L}}}{\mathrm{v}_{\text {Aacp }} \cos \phi_{\mathrm{L}}} .
$$

These quantities $\left(\mathrm{i}_{\mathrm{odc}}, \mathrm{i}_{\mathrm{o} 2 \mathrm{p}}\right.$ and $\left.\phi_{\mathrm{io} 2}\right)$ are of primary concern in the modelling of a PFC with voltage ripple on $\mathrm{v}_{\mathrm{A}}(\mathrm{t})$, because they determine its static and dynamic behaviour. The output voltage ripple amplitude and its phase lag angle can be easily calculated from (7) and (8):

$$
\begin{gathered}
\mathrm{v}_{\mathrm{o} 2 \mathrm{p}}=\frac{\mathrm{i}_{\mathrm{o} 2 \mathrm{p}}}{2 \mathrm{C}_{\mathrm{B}} \omega_{\mathrm{L}}}=\frac{\mathrm{v}_{\mathrm{o}}}{\mathrm{R}_{\mathrm{L}} \mathrm{C}_{\mathrm{B}} \omega_{\mathrm{L}}} \cdot \frac{\sqrt{1+\mathrm{k}^{2}+2 \mathrm{k} \sin \phi_{\mathrm{L}}}}{2+\mathrm{k} \sin \phi_{\mathrm{L}}}, \\
\phi_{\mathrm{vo} 2}=\phi_{\mathrm{io} 2}+\phi_{\mathrm{RLCB}} \approx \arctan \frac{1+\mathrm{k} \sin \phi_{\mathrm{L}}}{\mathrm{k} \cos \phi_{\mathrm{L}}}+\frac{\pi}{2},
\end{gathered}
$$

where $\mathrm{v}_{\mathrm{o} 2 \mathrm{p}}$ and $\phi_{\mathrm{vo} 2}$ are, respectively, the amplitude and phase lag angle of the voltage ripple component of twice the line frequency and $\phi_{\mathrm{RLCB}} \approx \pi / 2$ is the phase lag angle of the $\mathrm{C}_{\mathrm{B}}-\mathrm{R}_{\mathrm{L}}$ output cell at twice the line frequency. Moreover, the evaluation of the gain (magnitude and phase) of the output-voltage feedback loop at the ripple frequency [21] yields (see Fig. 1.a and Fig. 2):

$$
\begin{gathered}
\mathrm{v}_{\text {Aacp }}=\mathrm{v}_{\mathrm{o} 2 \mathrm{p}} \beta \mathrm{A}_{\mathrm{R} 2 \omega \mathrm{L}}, \\
\phi_{\mathrm{L}}=\phi_{\mathrm{v} 02}-\pi+\phi_{\mathrm{R} 2 \omega \mathrm{L}}=\arctan \frac{1+\mathrm{k} \sin \phi_{\mathrm{L}}}{\mathrm{k} \cos \phi_{\mathrm{L}}}-\frac{\pi}{2}+\phi_{\mathrm{R} 2 \omega \mathrm{L}},
\end{gathered}
$$

where $A_{R 2 \omega L}$ and $\phi_{R 2 \omega L}$ are the magnitude and the phase lag angle of $A_{R}$ at twice the line frequency (i.e., $\left.2 \omega_{L}\right)$. Moreover, the value of $\phi_{\mathrm{L}}$ can be found from (12) after using some trigonometric relationships and taking into account (5):

$$
\phi_{\mathrm{L}}=\operatorname{arcos}\left(\frac{\mathrm{v}_{\text {Aacp }}}{\mathrm{v}_{\mathrm{Adc}}} \cos \phi_{\mathrm{R} 2 \omega \mathrm{L}}\right)+\phi_{\mathrm{R} 2 \omega \mathrm{L}}-\frac{\pi}{2}
$$


The notation used in the following modelling process is the usual one, i.e., capital letters have been used to describe steady-state quantities, while lower-case letters with hats have been employed for the perturbations of the same quantities.

\section{Static behaviour}

The amplitude of the relative output-voltage ripple can be easily calculated taking into account the steady state of $\mathrm{v}_{\mathrm{o}}$ and $\mathrm{v}_{\mathrm{o} 2 \mathrm{p}}$ given in (6) and (9):

$$
\mathrm{r}_{\mathrm{v} 2}=\frac{\mathrm{V}_{\mathrm{o} 2 \mathrm{p}}}{\mathrm{V}_{\mathrm{o}}}=\frac{1}{\mathrm{R}_{\mathrm{L}} \mathrm{C}_{\mathrm{B}} \omega_{\mathrm{L}}} \cdot \frac{\sqrt{1+\mathrm{K}^{2}+2 \mathrm{~K} \sin \Phi_{\mathrm{L}}}}{2+\mathrm{K} \sin \Phi_{\mathrm{L}}} .
$$

where $\mathrm{K}$ and $\Phi_{\mathrm{L}}$ are the steady-state values of $\mathrm{k}$ and $\phi_{\mathrm{L}}$. Moreover, the steady-state versions of (11) and (12) allow us to determine the gain (magnitude and phase lag angle) of the error amplifier at $2 \omega_{\mathrm{L}}$ (i.e., $\mathrm{A}_{\mathrm{R} 2 \omega \mathrm{L}}$ and $\phi_{\mathrm{R} 2 \omega \mathrm{L}}$ ) from given values of $\mathrm{K}$ and $\Phi_{\mathrm{L}}$, as follows:

$$
\begin{aligned}
\mathrm{A}_{\mathrm{R} 2 \omega \mathrm{L}} & =\frac{\mathrm{V}_{\mathrm{Adc}} \mathrm{K}}{\mathrm{V}_{\mathrm{o} 2 \mathrm{p}} \beta}=\frac{\mathrm{V}_{\mathrm{Adc}} \mathrm{K}}{\mathrm{r}_{\mathrm{v} 2} \mathrm{~V}_{\mathrm{o}} \beta}, \\
\phi_{\mathrm{R} 2 \omega \mathrm{L}} & =\Phi_{\mathrm{L}}+\frac{\pi}{2}-\arctan \frac{1+\mathrm{K} \sin \Phi_{\mathrm{L}}}{\mathrm{K} \cos \Phi_{\mathrm{L}}} .
\end{aligned}
$$

As previously mentioned, the voltage ripple on the control signal $\mathrm{v}_{\mathrm{A}}$ causes line current distortion at the input of the PFC. From (2-6), the steady-state value of the current at the input of the power stage, $i_{g}\left(\omega_{L} t\right)$, and of the line current, $i_{g L}\left(\omega_{L} t\right)$, (see Fig.1.a) can be easily calculated:

$$
\begin{gathered}
\left.I_{g}\left(\omega_{L} t\right)=\frac{4 V_{o}^{2}}{V_{g p} R_{L}} \cdot \frac{\left[1+K \sin \left(2 \omega_{L} t-\Phi_{L}\right)\right]}{\left(2+K \sin \Phi_{L}\right)} \mid \sin \omega_{L} t\right) \\
I_{g L}\left(\omega_{L} t\right)=\frac{4 V_{o}^{2}}{V_{g p} R_{L}} \cdot \frac{\left[1+K \sin \left(2 \omega_{L} t-\Phi_{L}\right)\right]}{\left(2+K \sin \Phi_{L}\right)} \sin \omega_{L} t .
\end{gathered}
$$

Equation (18) shows that the steady-state value of the input current only has components of $\omega_{\mathrm{L}}$ and $3 \omega_{\mathrm{L}}$. After applying some trigonometric relationships, the amplitude of its first and third harmonic can be easily calculated:

$$
\begin{aligned}
& I_{g L 1 p}=\frac{4 V_{o}^{2}}{V_{g p} R_{L}} \cdot \frac{\sqrt{1+0.25 K^{2}+K \sin \Phi_{L}}}{\left(2+K \sin \Phi_{L}\right)}, \\
& I_{g L 3 p}=\frac{2 V_{o}^{2}}{V_{g p} R_{L}} \cdot \frac{K}{\left(2+K \sin \Phi_{L}\right)} .
\end{aligned}
$$

Moreover, the rms value of the line current in steady-state will be: 


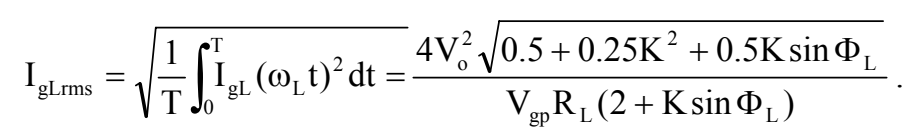

Equations (19), (20) and (21) are of primary concern to determine compliance with the regulations regarding line current distortion.

\section{Dynamic behaviour}

The average small-signal model of a PFC with appreciable voltage ripple in the output-voltage feedback loop was obtained in [22] following a similar process to that proposed in [25]. However, the process followed in the present case has taken into account the influence of the variations (perturbations) of not only $\mathrm{v}_{\mathrm{Adc}}$, but also the variations of $\mathrm{v}_{\text {Aacp }}$ and $\phi_{\mathrm{L}}$ in the modelling process. The first stage of the modelling process is to perturb both the dc and ac components of the current injected into the output $C_{B}-R_{L}$ cell given by (6) and (7):

$$
\begin{aligned}
& \hat{\mathrm{i}}_{\text {odc }}=\mathrm{G}_{1} \hat{\mathrm{v}}_{\mathrm{gp}}+\mathrm{G}_{2} \hat{\mathrm{v}}_{\text {Adc }}+\mathrm{G}_{3} \hat{\mathrm{v}}_{\text {Aacp }}+\mathrm{G}_{4} \hat{\phi}_{\mathrm{L}}+\mathrm{G}_{5} \hat{\mathrm{v}}_{\mathrm{o}}, \\
& \hat{\mathrm{i}}_{\mathrm{o} 2 \mathrm{p}}=\mathrm{G}_{7} \hat{\mathrm{v}}_{\mathrm{gp}}+\mathrm{G}_{8} \hat{\mathrm{v}}_{\text {Adc }}+\mathrm{G}_{9} \hat{\mathrm{v}}_{\text {Aacp }}+\mathrm{G}_{10} \hat{\phi}_{\mathrm{L}}+\mathrm{G}_{11} \hat{\mathrm{v}}_{\mathrm{o}},
\end{aligned}
$$

where the value of the partial transfer function $G_{x}$ are shown in Table 1. The perturbed values of the dc component of the output voltage $\mathrm{v}_{\mathrm{o}}$ are related to the perturbed value of $\mathrm{i}_{\mathrm{odc}}$ through the following equation:

$$
\hat{\mathrm{v}}_{\text {odc }}=\mathrm{G}_{6}(\mathrm{~s}) \hat{\mathrm{i}}_{\text {odc }}=\frac{\mathrm{R}_{\mathrm{L}}}{1+\mathrm{R}_{\mathrm{L}} \mathrm{C}_{\mathrm{B}} \mathrm{s}} \hat{\mathrm{i}}_{\text {odc }},
$$

and the perturbations of the output voltage ripple are related to the perturbed value of $\mathrm{i}_{02 \mathrm{p}}$ through the impedance of the output $\mathrm{C}_{\mathrm{B}^{-}}$ $\mathrm{R}_{\mathrm{L}}$ cell at twice the line frequency:

$$
\begin{aligned}
& \mathrm{G}_{1}=\frac{2 \mathrm{~V}_{\mathrm{o}}}{\mathrm{V}_{\mathrm{gp}} \mathrm{R}_{\mathrm{L}}} \quad \mathrm{G}_{2}=\frac{2 \mathrm{~V}_{\mathrm{o}}}{\mathrm{V}_{\mathrm{Adc}} \mathrm{R}_{\mathrm{L}}\left(2+\mathrm{K} \sin \Phi_{\mathrm{L}}\right)} \quad \mathrm{G}_{3}=\frac{\mathrm{V}_{\mathrm{o}} \sin \Phi_{\mathrm{L}}}{\mathrm{V}_{\mathrm{Adc}} \mathrm{R}_{\mathrm{L}}\left(2+\mathrm{K} \sin \Phi_{\mathrm{L}}\right)} \quad \mathrm{G}_{4}=\frac{\mathrm{V}_{\mathrm{o}} \mathrm{K} \cos \Phi_{\mathrm{L}}}{\mathrm{R}_{\mathrm{L}}\left(2+\mathrm{K} \sin \Phi_{\mathrm{L}}\right)} \quad \mathrm{G}_{5}=-\frac{1}{\mathrm{R}_{\mathrm{L}}} \\
& \mathrm{G}_{6}(\mathrm{~s})=\frac{\mathrm{R}_{\mathrm{L}}}{1+\mathrm{sR}_{\mathrm{L}} \mathrm{C}_{\mathrm{B}}} \quad \mathrm{G}_{7}=\frac{4 \mathrm{~V}_{\mathrm{o}} \sqrt{1+\mathrm{K}^{2}+2 \mathrm{~K} \sin \Phi_{\mathrm{L}}}}{\mathrm{V}_{\mathrm{gp}} \mathrm{R}_{\mathrm{L}}\left(2+\mathrm{K} \sin \Phi_{\mathrm{L}}\right)} \quad \mathrm{G}_{8}=\frac{2 \mathrm{~V}_{\mathrm{o}}\left(1+\mathrm{K} \sin \Phi_{\mathrm{L}}\right)}{\mathrm{V}_{\mathrm{Adc}} \mathrm{R}_{\mathrm{L}}\left(2+\mathrm{K} \sin \Phi_{\mathrm{L}}\right) \sqrt{1+\mathrm{K}^{2}+2 \mathrm{~K} \sin \Phi_{\mathrm{L}}}} \\
& \mathrm{G}_{9}=\frac{2 \mathrm{~V}_{\mathrm{o}}\left(\mathrm{K}+\sin \Phi_{\mathrm{L}}\right)}{\mathrm{V}_{\mathrm{Adc}} \mathrm{R}_{\mathrm{L}}\left(2+\mathrm{K} \sin \Phi_{\mathrm{L}}\right) \sqrt{1+\mathrm{K}^{2}+2 \mathrm{~K} \sin \Phi_{\mathrm{L}}}} \quad \mathrm{G}_{10}=\frac{2 \mathrm{~V}_{\mathrm{o}} \mathrm{K} \cos \Phi_{\mathrm{L}}}{\mathrm{R}_{\mathrm{L}}\left(2+\mathrm{K} \sin \Phi_{\mathrm{L}}\right) \sqrt{1+\mathrm{K}^{2}+2 \mathrm{~K} \sin \Phi_{\mathrm{L}}}} \quad \mathrm{G}_{11}=-\frac{2 \sqrt{1+\mathrm{K}^{2}+2 \mathrm{~K} \sin \Phi_{\mathrm{L}}}}{\mathrm{R}_{\mathrm{L}}\left(2+\mathrm{K} \sin \Phi_{\mathrm{L}}\right)} \\
& \mathrm{G}_{12}=\frac{\mathrm{K} \cos \Phi_{\mathrm{L}}}{\mathrm{V}_{\mathrm{Adc}}\left(1+\mathrm{K} \sin \Phi_{\mathrm{L}}\right)} \quad \mathrm{G}_{13}=\frac{-\cos \Phi_{\mathrm{L}}}{\mathrm{V}_{\mathrm{Adc}}\left(1+\mathrm{K} \sin \Phi_{\mathrm{L}}\right)} \quad \mathrm{G}_{14}=\frac{1}{2 \mathrm{C}_{\mathrm{B}} \omega_{\mathrm{L}}}
\end{aligned}
$$

Table 1: Partial transfer functions obtained in the average small-signal modelling. 


$$
\hat{\mathrm{v}}_{\mathrm{o} 2 \mathrm{p}}=\mathrm{G}_{14} \hat{\mathrm{i}}_{\mathrm{o} 2 \mathrm{p}}=\frac{1}{2 \mathrm{C}_{\mathrm{B}} \omega_{\mathrm{L}}} \hat{\mathrm{i}}_{\mathrm{o} 2 \mathrm{p}} \text {, }
$$

Moreover, the variations of $\mathrm{v}_{\mathrm{o} 2 \mathrm{p}}$ and $\mathrm{v}_{\text {Aacp }}$ are related by the feedback loop through (11) and the variations of $\mathrm{v}_{\mathrm{Adc}}, \mathrm{v}_{\mathrm{Aacp}}$ and $\phi_{\mathrm{L}}$ are related to each other through (13):

$$
\begin{gathered}
\hat{\mathrm{v}}_{\text {Aacp }}=\mathrm{A}_{\mathrm{R} 2 \omega \mathrm{L}} \beta \hat{\mathrm{v}}_{\mathrm{o} 2 \mathrm{p}}, \\
\hat{\phi}_{\mathrm{L}}=\mathrm{G}_{12} \hat{\mathrm{v}}_{\text {Adc }}+\mathrm{G}_{13} \hat{\mathrm{v}}_{\text {Aacp }} .
\end{gathered}
$$

The relationships obtained between all the perturbed quantities can be summarized in the block diagram shown in Fig. 3 . As this figure shows, a "parasitic" feedback loop (with several branches) appears. However, this complex block diagram can be reduced to a simpler one, as in Fig. 4 [22]. The values of the main functions shown in this figure are given in Table 2. As this table shows, the transfer function between the control and the dc output voltage (i.e., $G_{v A d c}(s)$ ), the open-loop output impedance (i.e., $Z_{o}(s)$ ) and the frequency of the power stage pole (i.e., $\omega_{\mathrm{P}}$ ) depend on the static value of $\mathrm{k}$ and $\phi_{\mathrm{L}}$ (i.e., $\mathrm{K}=\mathrm{V}_{\text {Aacp }} / \mathrm{V}_{\text {Adc }}$ and $\Phi_{\mathrm{L}}$ ) through the

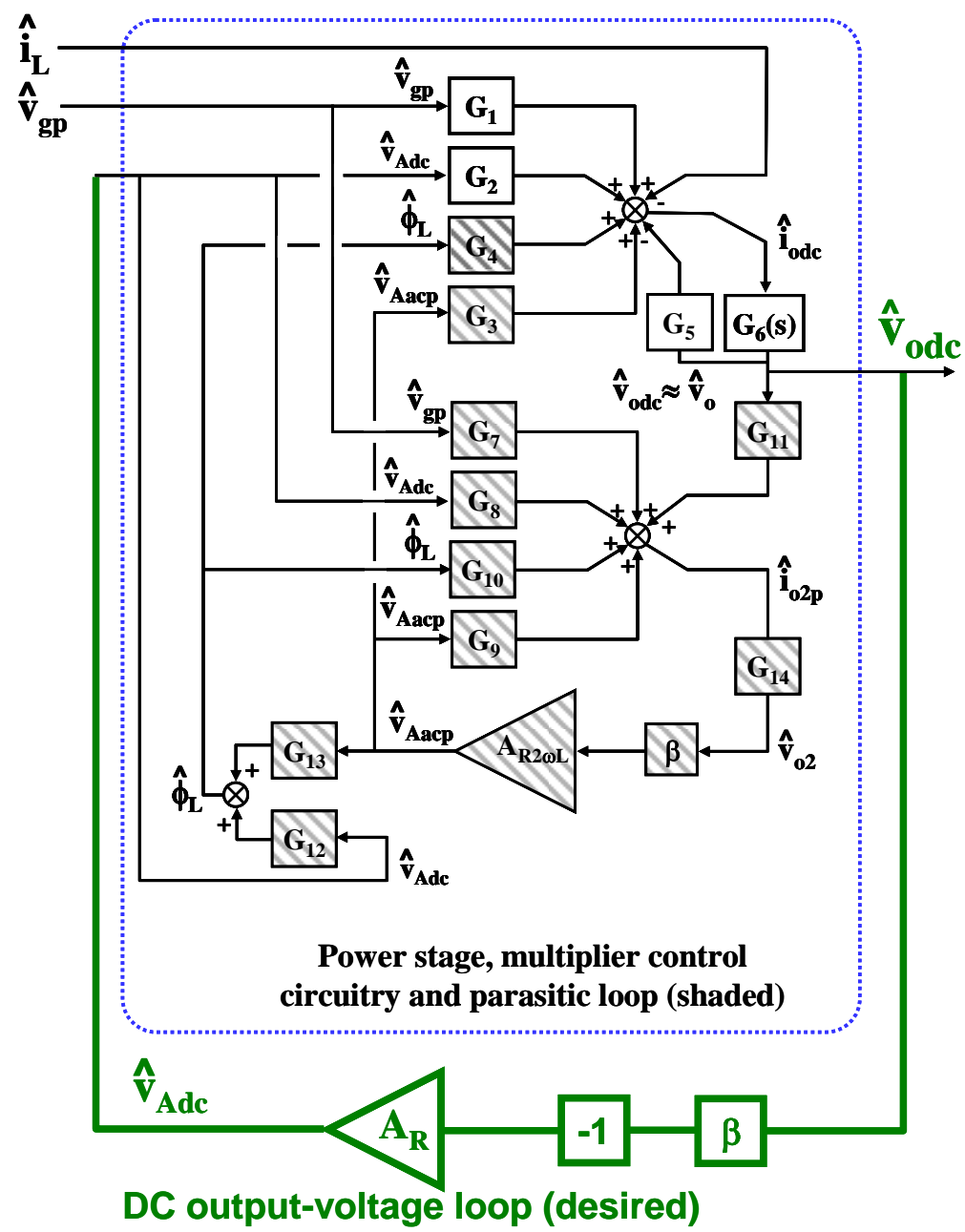

Fig. 3: Block diagram obtained establishing the relationships between all the perturbed quantities. 
dimensionless parameter $\mu$ (see Table 2). Similarly, the dimensionless parameter $\sigma$ determines the transfer function between input and output voltage.

The values of $\mu$ for different values of $\mathrm{K}$ and $\Phi_{\mathrm{L}}$ are given in Fig. 5. As this figure shows, $\mu$ becomes 1 when the relative ripple

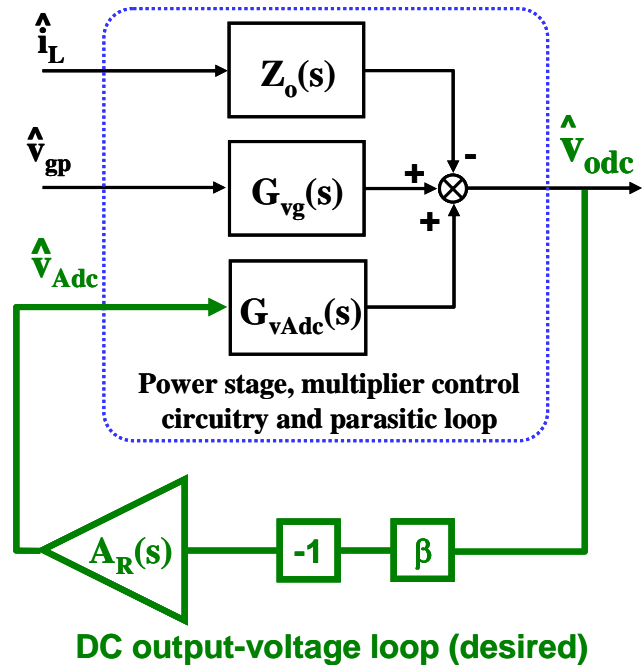

Fig. 4: Final block diagram.

$$
\begin{aligned}
& \mathrm{G}_{\mathrm{vAdc}}(\mathrm{s})=\frac{\mathrm{V}_{\mathrm{o}}}{2 \mathrm{~V}_{\mathrm{Adc}} \mu} \cdot \frac{1}{1+\frac{\mathrm{s}}{\omega_{\mathrm{P}}}} \quad \mathrm{G}_{\mathrm{vg}}(\mathrm{s})=\frac{\mathrm{V}_{\mathrm{o}} \sigma}{\mathrm{V}_{\mathrm{gp}}} \cdot \frac{1}{1+\frac{\mathrm{s}}{\omega_{\mathrm{P}}}} \\
& \mathrm{Z}_{\mathrm{o}}(\mathrm{s})=\frac{\mathrm{R}_{\mathrm{L}} \cdot \frac{1}{2 \mu}}{1+\frac{\mathrm{s}}{\omega_{\mathrm{P}}}} \quad \omega_{\mathrm{P}}=\frac{2 \mu}{\mathrm{C}_{\mathrm{B}} \mathrm{R}_{\mathrm{L}}} \\
& \mu=\frac{4+3 \mathrm{~K} \sin \Phi_{\mathrm{L}}+2 \mathrm{~K}^{2} \sin ^{2} \Phi_{\mathrm{L}}-\mathrm{K}^{2}}{2\left(2+\mathrm{K} \sin \Phi_{\mathrm{L}}\right)} \\
& \sigma=\frac{4+4 \mathrm{~K} \sin \Phi_{\mathrm{L}}+4 \mathrm{~K}^{2} \sin ^{2} \Phi_{\mathrm{L}}-2 \mathrm{~K}^{2}}{4+3 \mathrm{~K} \sin \Phi_{\mathrm{L}}+2 \mathrm{~K}^{2} \sin ^{2} \Phi_{\mathrm{L}}-\mathrm{K}^{2}}
\end{aligned}
$$

Table 2: Main transfer functions shown in Fig. 4 and some of their design parameters.

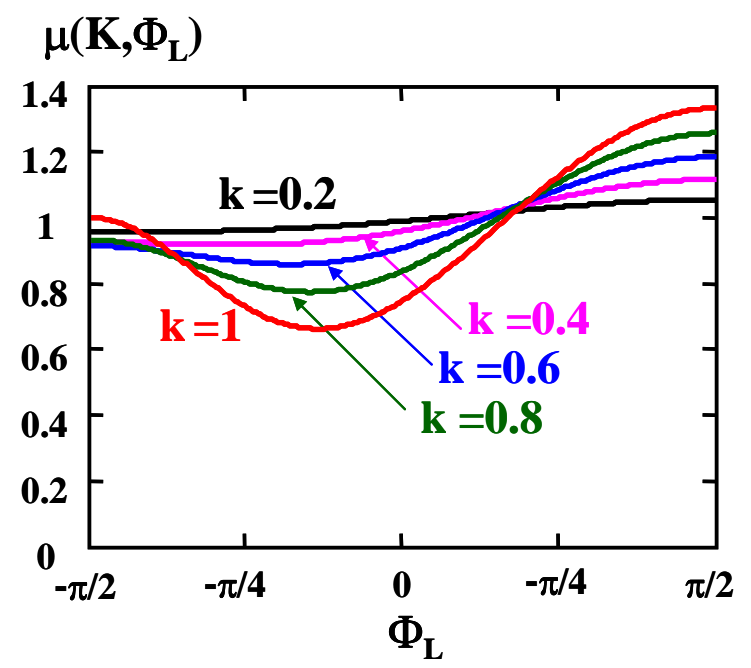

Fig. 5: Values of $\mu$ as a function of $\Phi_{\mathrm{L}}$ and $\mathrm{K}$. 
$\mathrm{K}$ is zero; in this case, the model thus obtained coincides with that obtained in [25] for PFCs with no ripple on $\mathrm{v}_{\mathrm{A}}$. The maximum value of $\mu$ is 1.33 (corresponding to $\mathrm{K}=1$ and $\Phi_{\mathrm{L}}=90^{\circ}$ ), whereas the minimum value of $\mu$ is 0.66 (corresponding to $\mathrm{K}=1$ and $\Phi_{\mathrm{L}}$ $\left.=-24.8^{\circ}\right)$.

\section{Modelling with line voltage feedforward}

The steady-state value of the average input power processed by the PFC shown in Fig. 1.a can be easily calculated from (1)-(5) as follows:

$$
P_{\text {gav }}=\frac{\omega_{L}}{\pi} \int_{0}^{\frac{\pi}{\omega_{L}}} V_{g}\left(\omega_{L} t\right) I_{g}\left(\omega_{L} t\right) d t=\frac{V_{g p}^{2} V_{A d c}}{4 K_{M}}\left(2+K \sin \Phi_{L}\right)
$$

As this equation shows, the value of $\mathrm{V}_{\mathrm{Adc}}$ strongly depends on the value of $\mathrm{V}_{\mathrm{gp}}$ for a given average input power. Due to this fact, the value of the $G_{\text {vAdc }}(s)$ (see Table 2) will vary when the line changes (e.g., from the values corresponding to the minimum American line voltage to the maximum European one, in the case of Universal line voltage). As is very well known [2], this problem can be overcome by adding an additional loop (see Fig. 6), which is a feedforward loop. Therefore, (2) becomes in this case:

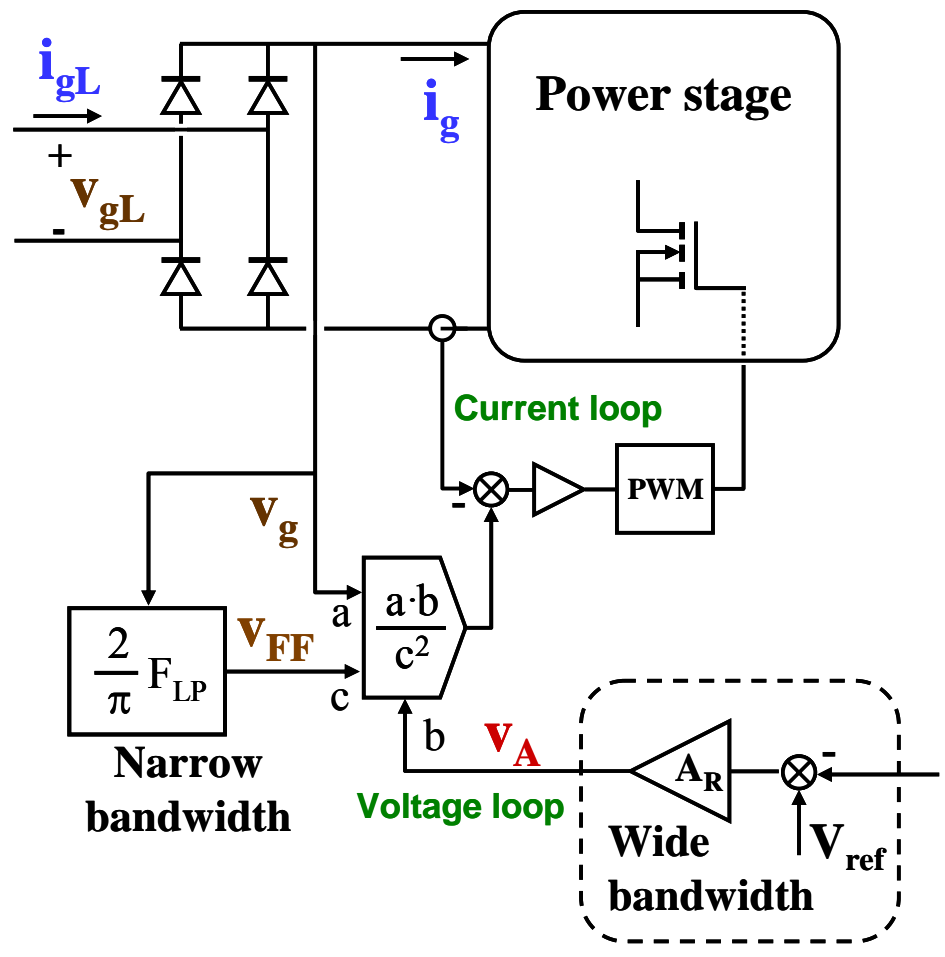

Fig. 6: Line voltage feedforward in the PFC shown in Fig. 1.a. 


$$
\mathrm{i}_{\mathrm{g}}\left(\omega_{\mathrm{L}} \mathrm{t}\right)=\frac{\mathrm{v}_{\mathrm{gp}}\left|\sin \left(\omega_{\mathrm{L}} \mathrm{t}\right)\right| \mathrm{v}_{\mathrm{A}}(\mathrm{t})}{\mathrm{K}_{\mathrm{M}}^{\prime} \mathrm{v}_{\mathrm{FF}}^{2}}
$$

where $\mathrm{K}_{\mathrm{M}}{ }_{\mathrm{M}}$ is a new constant determined by the controller (as in the case of $\mathrm{K}_{\mathrm{M}}$ in (2)) and $\mathrm{V}_{\mathrm{FF}}$ is the voltage coming from the rectified line voltage after passing through a low-pass filter to obtain its average value. This filter is assumed to remove all the ac components: therefore, the steady-state values of $\mathrm{v}_{\mathrm{FF}}$ and of the peak value of the line voltage (i.e., $\mathrm{v}_{\mathrm{gp}}$ ) are related as follows:

$$
\mathrm{V}_{\mathrm{FF}}=\frac{2}{\pi} \mathrm{V}_{\mathrm{gp}} .
$$

The only difference between (2) and (29) is that $\mathrm{K}_{\mathrm{M}}{ }_{\mathrm{V}}{ }^{2}$ FF appears in the denominator of the input current equation instead of $\mathrm{K}_{\mathrm{M}}$. As all the partial transfer functions can be expressed without using $\mathrm{K}_{\mathrm{M}}$, all of them retain the values given in Table 1 when line voltage feedforward is used. However, some differences arise due to the dynamics associated with the low-pass filter. Thus, (6) and (7) become:

$$
\begin{gathered}
\mathrm{i}_{\mathrm{odc}}=\frac{\mathrm{v}_{\mathrm{gp}}^{2} \mathrm{v}_{\mathrm{Adc}}}{4 \mathrm{~K}_{\mathrm{M}}^{\prime} \mathrm{v}_{\mathrm{FF}}^{2} \mathrm{v}_{\mathrm{o}}}\left(2+\frac{\mathrm{v}_{\text {Aacp }}}{\mathrm{v}_{\mathrm{Adc}}} \sin \phi_{\mathrm{L}}\right), \\
\mathrm{i}_{\mathrm{o} 2 \mathrm{p}}=\frac{\mathrm{v}_{\mathrm{gp}}^{2}}{2 \mathrm{~K}_{\mathrm{M}}^{\prime} \mathrm{v}_{\mathrm{FF}}^{2} \mathrm{v}_{\mathrm{o}}} \sqrt{\mathrm{v}_{\mathrm{Adc}}{ }^{2}+\mathrm{v}_{\text {Aacp }}{ }^{2}+2 \mathrm{v}_{\mathrm{Adc}} \mathrm{v}_{\text {Aacp }} \sin \phi_{\mathrm{L}}},
\end{gathered}
$$

After perturbing these equations and bearing in mind that the value of $\mathrm{v}_{\mathrm{FF}}$ can also be perturbed, we obtain:

$$
\begin{aligned}
& \hat{\mathrm{i}}_{\mathrm{odc}}=\mathrm{G}_{1} \hat{\mathrm{v}}_{\mathrm{gp}}+\mathrm{G}_{2} \hat{\mathrm{v}}_{\mathrm{Adc}}+\mathrm{G}_{3} \hat{\mathrm{v}}_{\text {Aacp }}+\mathrm{G}_{4} \hat{\phi}_{\mathrm{L}}+\mathrm{G}_{5} \hat{\mathrm{v}}_{\mathrm{o}}+\mathrm{G}_{\mathrm{FF} 1} \hat{\mathrm{v}}_{\mathrm{FF}}, \\
& \hat{\mathrm{i}}_{\mathrm{o} 2 \mathrm{p}}=\mathrm{G}_{7} \hat{\mathrm{v}}_{\mathrm{gp}}+\mathrm{G}_{8} \hat{\mathrm{v}}_{\mathrm{Adc}}+\mathrm{G}_{9} \hat{\mathrm{v}}_{\text {Aacp }}+\mathrm{G}_{10} \hat{\phi}_{\mathrm{L}}+\mathrm{G}_{11} \hat{\mathrm{v}}_{\mathrm{o}}+\mathrm{G}_{\mathrm{FF} 2} \hat{\mathrm{v}}_{\mathrm{FF}},
\end{aligned}
$$

where:

$$
\begin{gathered}
\left.\mathrm{G}_{\mathrm{FF} 1}=\frac{\partial \mathrm{i}_{\mathrm{odc}}}{\partial \mathrm{v}_{\mathrm{FF}}}\right]_{\mathrm{P}}=\frac{-\mathrm{V}_{\mathrm{gp}}^{2} \mathrm{~V}_{\mathrm{Adc}}}{2 \mathrm{~K}_{\mathrm{M}}^{\prime} \mathrm{V}_{\mathrm{o}} \mathrm{V}_{\mathrm{FF}}^{3}}\left(2+\mathrm{K} \sin \Phi_{\mathrm{L}}\right)=\frac{-2 \mathrm{~V}_{\mathrm{o}}}{\mathrm{V}_{\mathrm{FF}} \mathrm{R}_{\mathrm{L}}}, \\
\left.\mathrm{G}_{\mathrm{FF} 2}=\frac{\partial \mathrm{i}_{\mathrm{o} 2 \mathrm{p}}}{\partial \mathrm{v}_{\mathrm{FF}}}\right]_{\mathrm{P}}=\frac{-4 \mathrm{~V}_{\mathrm{o}} \sqrt{1+\mathrm{K}^{2}+2 \mathrm{~K} \sin \Phi_{\mathrm{L}}}}{\mathrm{V}_{\mathrm{FF}} \mathrm{R}_{\mathrm{L}}\left(2+\mathrm{K} \sin \Phi_{\mathrm{L}}\right)}=\frac{-2 \mathrm{I}_{\mathrm{o} 2 \mathrm{p}}}{\mathrm{V}_{\mathrm{FF}}}
\end{gathered}
$$

the rest of the partial transfer function $\mathrm{G}_{\mathrm{x}}$ being the same as those shown in Table 1. Comparing the values of $\mathrm{G}_{\mathrm{FF} 1}, \mathrm{G}_{1}, \mathrm{G}_{\mathrm{FF} 2}$ and $\mathrm{G}_{7}$ and taking into account (30), (35) and (36) become: 


$$
\begin{aligned}
\mathrm{G}_{\mathrm{FF} 1} & =-\frac{\pi}{2} \mathrm{G}_{1}, \\
\mathrm{G}_{\mathrm{FF} 2} & =-\frac{\pi}{2} \mathrm{G}_{7},
\end{aligned}
$$

Moreover, the perturbations of $\mathrm{v}_{\mathrm{gp}}$ and $\mathrm{v}_{\mathrm{FF}}$ are related through the average-to-peak conversion ratio of a half-sinusoid (i.e., $2 / \pi$ ) and the low-pass filter transfer function (i.e., $\left.\mathrm{F}_{\mathrm{LP}}(\mathrm{s})\right)$ as follows:

$$
\hat{\mathrm{v}}_{\mathrm{FF}}=\frac{2}{\pi} \mathrm{F}_{\mathrm{LP}}(\mathrm{s}) \hat{\mathrm{v}}_{\mathrm{gp}},
$$

Substituting (37), (38) and (39) in (33) and (34), we obtain:

$$
\begin{aligned}
& \hat{\mathrm{i}}_{\mathrm{odc}}=\mathrm{G}_{1}^{\prime}(\mathrm{s}) \hat{\mathrm{v}}_{\mathrm{gp}}+\mathrm{G}_{2} \hat{\mathrm{v}}_{\mathrm{Adc}}+\mathrm{G}_{3} \hat{\mathrm{v}}_{\text {Aacp }}+\mathrm{G}_{4} \hat{\phi}_{\mathrm{L}}+\mathrm{G}_{5} \hat{\mathrm{v}}_{\mathrm{o}}, \\
& \hat{\mathrm{i}}_{\mathrm{o} 2 \mathrm{p}}=\mathrm{G}_{7}^{\prime}(\mathrm{s}) \hat{\mathrm{v}}_{\mathrm{gp}}+\mathrm{G}_{8} \hat{\mathrm{v}}_{\mathrm{Adc}}+\mathrm{G}_{9} \hat{\mathrm{v}}_{\text {Aacp }}+\mathrm{G}_{10} \hat{\phi}_{\mathrm{L}}+\mathrm{G}_{11} \hat{\mathrm{v}}_{\mathrm{o}},
\end{aligned}
$$

where:

$$
\begin{aligned}
& \mathrm{G}_{1}^{\prime}(\mathrm{s})=\mathrm{G}_{1}+\frac{2}{\pi} \mathrm{F}_{\mathrm{LP}}(\mathrm{s}) \mathrm{G}_{\mathrm{FF} 1}=\mathrm{G}_{1}\left(1-\mathrm{F}_{\mathrm{LP}}(\mathrm{s})\right), \\
& \mathrm{G}_{7}^{\prime}(\mathrm{s})=\mathrm{G}_{7}+\frac{2}{\pi} \mathrm{F}_{\mathrm{LP}}(\mathrm{s}) \mathrm{G}_{\mathrm{FF} 2}=\mathrm{G}_{7}\left(1-\mathrm{F}_{\mathrm{LP}}(\mathrm{s})\right) .
\end{aligned}
$$

Therefore, the block diagram shown in Fig. 3 is also valid for the case of having line voltage feedforward if we replace $\mathrm{G}_{1}$ and $\mathrm{G}_{7}$ with $\mathrm{G}_{1}{ }_{1}(\mathrm{~s})$ and $\mathrm{G}_{7}{ }_{7}(\mathrm{~s})$, respectively. As the transfer function of the low-pass filter at dc is 1 (i.e., $\left.\mathrm{F}_{\mathrm{LP}}(0)=1\right)$, then $\mathrm{G}_{1}{ }_{1}(0)=0$ and $\mathrm{G}_{7}^{\prime}(0)=0$, which means that the feedforward cancels the influence of the line voltage over the output voltage in steady-state conditions. On the other hand, when the peak value of the line voltage varies relatively fast, then $\mathrm{F}_{\mathrm{LP}}(\mathrm{s})<<1$ (low-pass filter) and the PFC operates as in the case of not having line voltage feedforward (i.e., $G^{\prime}{ }_{1}(s)=G_{1}$ and $\left.G^{\prime}{ }_{7}(s)=G_{7}\right)$.

The reduction of the block diagram shown in Fig. 3 to obtain the one shown in Fig. 4 is also valid in this case. The only change in the values of the final blocks given in Table 2 corresponds to the transfer function $\mathrm{G}_{\mathrm{vg}}(\mathrm{s})$, whose value is now:

$$
\mathrm{G}_{\mathrm{vg}}(\mathrm{s})=\frac{\mathrm{V}_{\mathrm{o}} \sigma}{\mathrm{V}_{\mathrm{gp}}} \cdot \frac{\left(1-\mathrm{F}_{\mathrm{LP}}(\mathrm{s})\right)}{1+\frac{\mathrm{s}}{\omega_{\mathrm{P}}}} .
$$

This final transfer function also shows that the line voltage feedforward will cancel slow line voltage variations $\left(\mathrm{F}_{\mathrm{LP}}(\mathrm{s}) \approx 1\right)$ and that it will not cancel fast line voltage variations $\left(\mathrm{F}_{\mathrm{LP}}(\mathrm{s}) \approx 0\right)$. 


\section{Closing the OUtPut-Voltage FeEdBACK LoOP}

Once the average small-signal model is known, the next step is to close the feedback loop. Let us assume a standard compensator such as the one shown in Fig. 1.c (PI with one additional pole), the transfer function of which is:

$$
\left.A_{R}(s)=\frac{v_{A}(s)}{v_{E}(s)}=\frac{v_{A}(s)}{-v_{o}(s) \beta}\right]_{V_{R F F}=0}=\frac{A_{R m}\left(1+\frac{s}{\omega_{A z}}\right)}{\frac{s}{\omega_{A z}}\left(1+\frac{s}{\omega_{A p}}\right)} .
$$

The zero defined by $\omega_{\mathrm{Az}}$ is usually chosen to minimize the dc error in $\mathrm{V}_{\mathrm{o}}$ and its angular frequency is much lower than the angular frequency of the main error amplifier pole $\omega_{\mathrm{Ap}}$ (e.g., $\omega_{\mathrm{Az}}=\omega_{\mathrm{Ap}} / 50$, as shown in Fig. 7). This means that the behaviour of $A_{R}$ at frequencies around the crossover frequency of the voltage feedback loop will be dominated by $A_{R m}$ and $\omega_{A p}$. Thus, we can approximate $\mathrm{A}_{\mathrm{R}}(\mathrm{s})$ as follows:

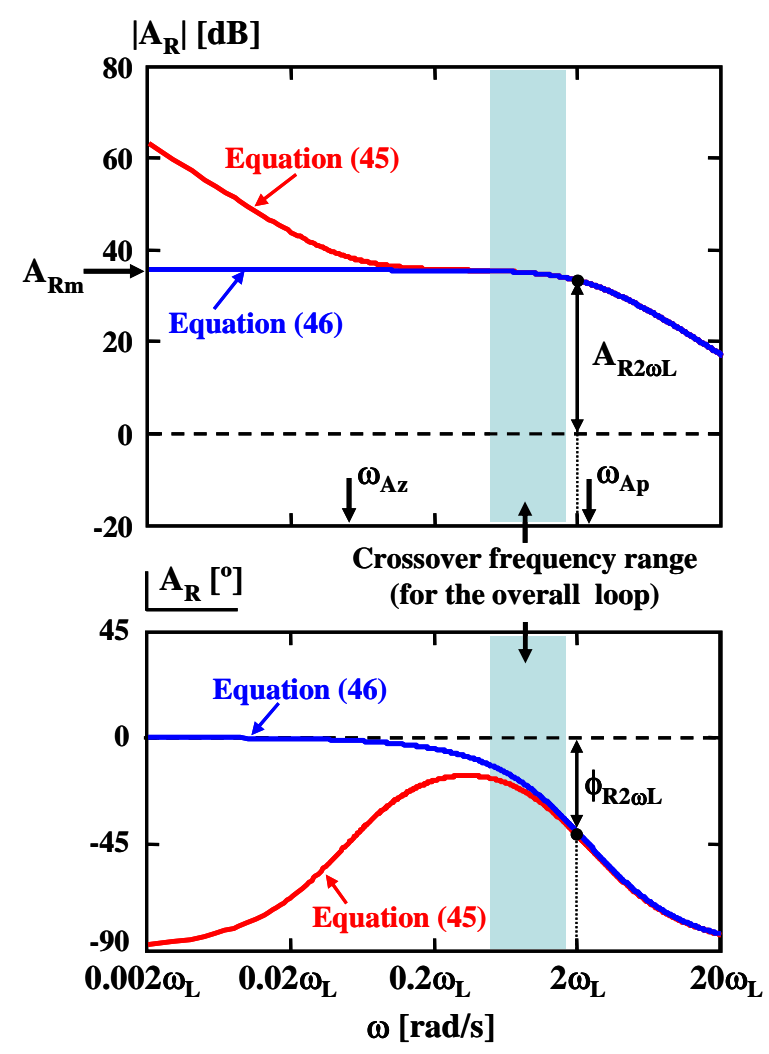

Fig. 7: Bode plots corresponding to the compensator shown in Fig. 1.c (Equation (45)) and its approximate values near the crossover frequency of the overall loop (Equation (46)). 


$$
A_{R}(s)=\frac{A_{R m}}{1+\frac{s}{\omega_{A p}}} .
$$

Therefore, the loop gain will be:

$$
\mathrm{T}(\mathrm{s})=\beta \mathrm{A}_{\mathrm{R}}(\mathrm{s}) \mathrm{G}_{\mathrm{VAdc}}(\mathrm{s})=\beta \frac{\mathrm{A}_{\mathrm{Rm}}}{1+\frac{\mathrm{s}}{\omega_{\mathrm{Ap}}}} \cdot \frac{\mathrm{V}_{\mathrm{o}}}{2 \mathrm{~V}_{\mathrm{Adc}} \mu} \cdot \frac{1}{1+\frac{\mathrm{s}}{\omega_{\mathrm{P}}}} .
$$

The magnitude and the phase lag angle of $\mathrm{T}(\mathrm{s})$ in the frequency domain will be:

$$
\begin{gathered}
|\mathrm{T}(\omega)|=\beta \frac{\mathrm{A}_{\mathrm{Rm}}}{\sqrt{1+\left(\frac{\omega}{\omega_{\mathrm{Ap}}}\right)^{2}}} \cdot \frac{\mathrm{V}_{\mathrm{o}}}{2 \mathrm{~V}_{\mathrm{Adc}} \mu} \cdot \frac{1}{\sqrt{1+\left(\frac{\omega}{\omega_{\mathrm{P}}}\right)^{2}}}, \\
\phi_{\mathrm{T}}(\omega)=\arctan \left(\frac{\omega}{\omega_{\mathrm{Ap}}}\right)+\arctan \left(\frac{\omega}{\omega_{\mathrm{P}}}\right) .
\end{gathered}
$$

The Bode plots corresponding to the transfer function between the output voltage $v_{\mathrm{o}}$ and the control voltage $\mathrm{v}_{\mathrm{A}}\left(\mathrm{i} . \mathrm{e}\right.$., $\left.\mathrm{G}_{\mathrm{vAdc}}(\mathrm{s})\right)$ are given in Fig. 8.a, whereas Fig. 8.b shows the Bode plots corresponding to T(s). As this figure shows, (46) can be used instead of (45) to determine the loop stability because both equations coincide near the crossover frequency $\omega_{0}$.

Also in the frequency domain, the magnitude and the phase lag angle of $A_{R}(s)$ at twice the line frequency (see Fig. 7) can be easily calculated from (46):

$$
\begin{aligned}
& A_{\mathrm{R} 2 \omega \mathrm{L}}=\frac{\mathrm{A}_{\mathrm{Rm}}}{\sqrt{1+\left(\frac{2 \omega_{\mathrm{L}}}{\omega_{\mathrm{Ap}}}\right)^{2}}}, \\
& \phi_{\mathrm{R} 2 \omega \mathrm{L}}=\arctan \left(\frac{2 \omega_{\mathrm{L}}}{\omega_{\mathrm{Ap}}}\right) .
\end{aligned}
$$

Taking into account (50) and (15), (48) becomes:

$$
|\mathrm{T}(\omega)|=\frac{\mathrm{K} \sqrt{1+\left(\frac{2 \omega_{\mathrm{L}}}{\omega_{\mathrm{Ap}}}\right)^{2}}}{2 \mu \mathrm{r}_{\mathrm{v} 2} \sqrt{1+\left(\frac{\omega}{\omega_{\mathrm{Ap}}}\right)^{2}} \sqrt{1+\left(\frac{\omega}{\omega_{\mathrm{P}}}\right)^{2}}} .
$$




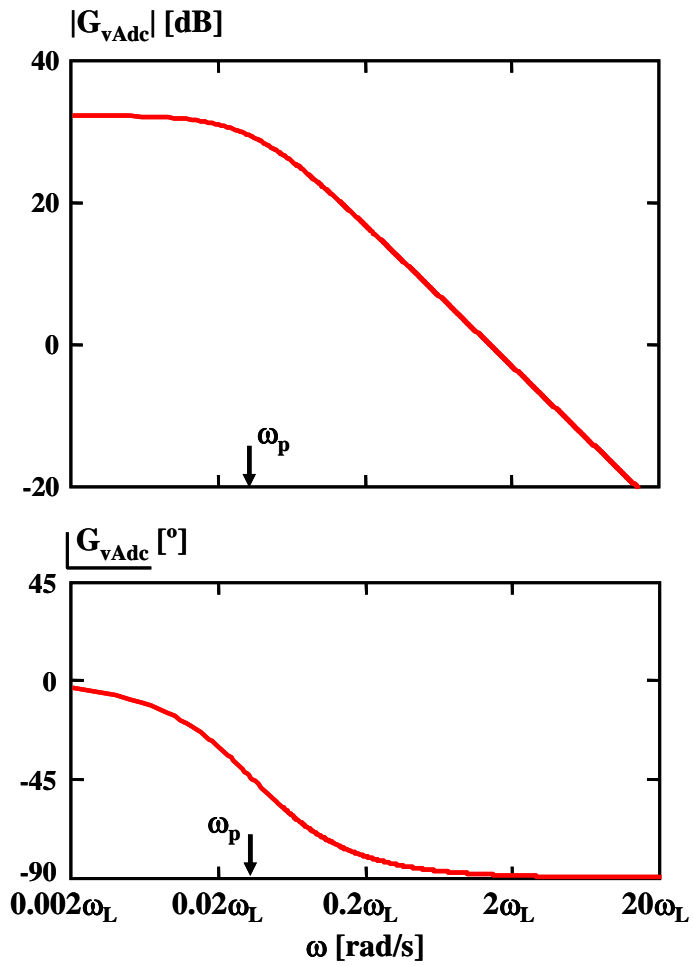

(a)

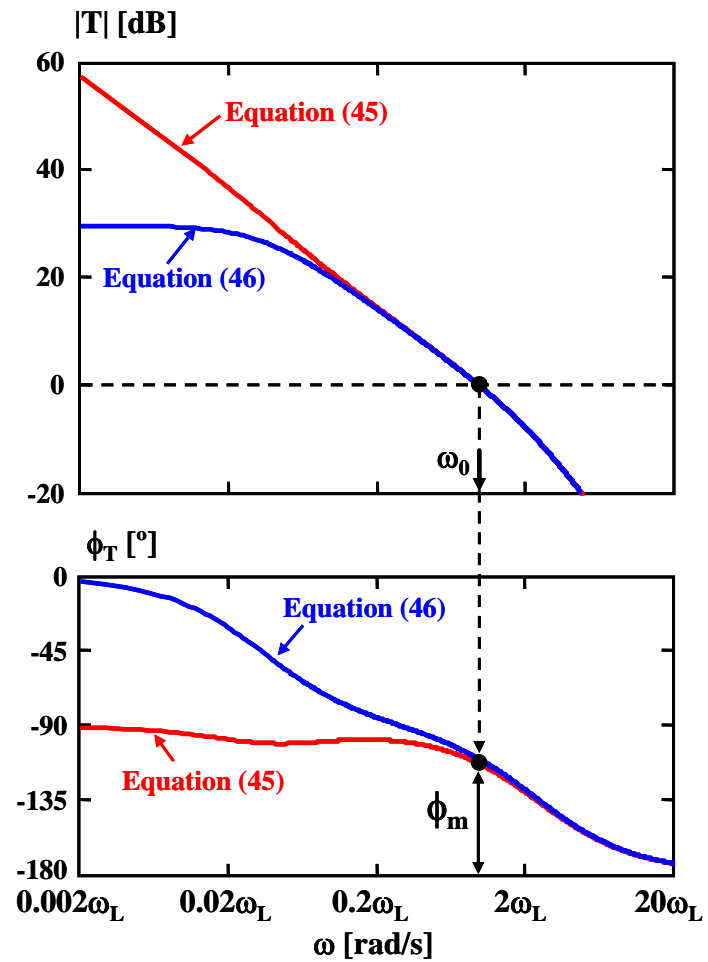

(b)

Fig. 8: a) Bode plots corresponding to the power stage. b) Bode plots corresponding to the overall feedback loop when $A_{R}$ is approximated by Equations (45) and (46).

Moreover, the value $\omega_{\mathrm{Ap}}$ can now be calculated from (16) and (51) after taking into account some trigonometric relationships:

$$
\omega_{\mathrm{Ap}}=2 \omega_{\mathrm{L}} \tan \left(-\Phi_{\mathrm{L}}+\arctan \frac{1+\mathrm{K} \sin \Phi_{\mathrm{L}}}{\mathrm{K} \cos \Phi_{\mathrm{L}}}\right)
$$

Finally, from the definition of crossover angular frequency $\left(\omega_{0}\right)$ and phase margin $\left(\phi_{\mathrm{m}}\right)$, we obtain (see Fig. 8.b):

$$
\begin{gathered}
\left|\mathrm{T}\left(\omega_{0}\right)\right|=1=\frac{\mathrm{K} \sqrt{1+\left(\frac{2 \omega_{\mathrm{L}}}{\omega_{\mathrm{Ap}}}\right)^{2}}}{2 \mu \mathrm{r}_{\mathrm{v} 2} \sqrt{1+\left(\frac{\omega_{0}}{\omega_{\mathrm{Ap}}}\right)^{2}} \sqrt{1+\left(\frac{\omega_{0}}{\omega_{\mathrm{P}}}\right)^{2}}}, \\
\phi_{\mathrm{m}}=\pi-\phi_{\mathrm{T}}\left(\omega_{0}\right)=\pi-\arctan \left(\frac{\omega_{0}}{\omega_{\mathrm{Ap}}}\right)-\arctan \left(\frac{\omega_{0}}{\omega_{\mathrm{P}}}\right) .
\end{gathered}
$$

We now have a system of 8 simultaneous equations (i.e., (14), (15), (50), (53), (54), (55) and the definitions of $\mu$ and $\omega_{\mathrm{P}}$ in Table 2), 8 known parameters (i.e., the line angular frequency $\omega_{L}$, the load resistance $R_{L}$, the output voltage $V_{o}$, the gain of output- 
voltage sensor $\beta$, the desired dc value of the control voltage $\mathrm{V}_{\mathrm{Adc}}$, the desired phase margin $\phi_{\mathrm{m}}$, the desired crossover angular frequency $\omega_{0}$, and the desired relative output ripple $\left.r_{v}\right)$ and 8 unknown variables $\left(K, \Phi_{L}, \mu, A_{R 2 \omega L}, A_{R m}, \omega_{A p}, \omega_{P}\right.$ and $\left.C_{B}\right)$. Therefore, the design of the voltage feedback loop can now be carried out.

After solving the aforementioned system of simultaneous equations using Mathcad, we obtain the plots given in Fig. 9.a and Fig. 9.b. The former shows the required values of $\mathrm{K}$ as a function of both the desired phase margin $\phi_{\mathrm{m}}$ and of the desired normalized crossover frequency $\omega_{0} / \omega_{\mathrm{L}}$, whereas the latter shows the required values of $\Phi_{\mathrm{L}}$ also as a function of the desired values of both $\phi_{\mathrm{m}}$ and $\omega_{0} / \omega_{\mathrm{L}}$. Both figures show that the maximum crossover frequency with a reasonable phase margin is always around $1.5 \omega_{\mathrm{L}}$, because $\mathrm{K}$ must always be smaller than 1 (this is because the instantaneous value of $\mathrm{v}_{\mathrm{A}}$ cannot be negative). In summary, the plots
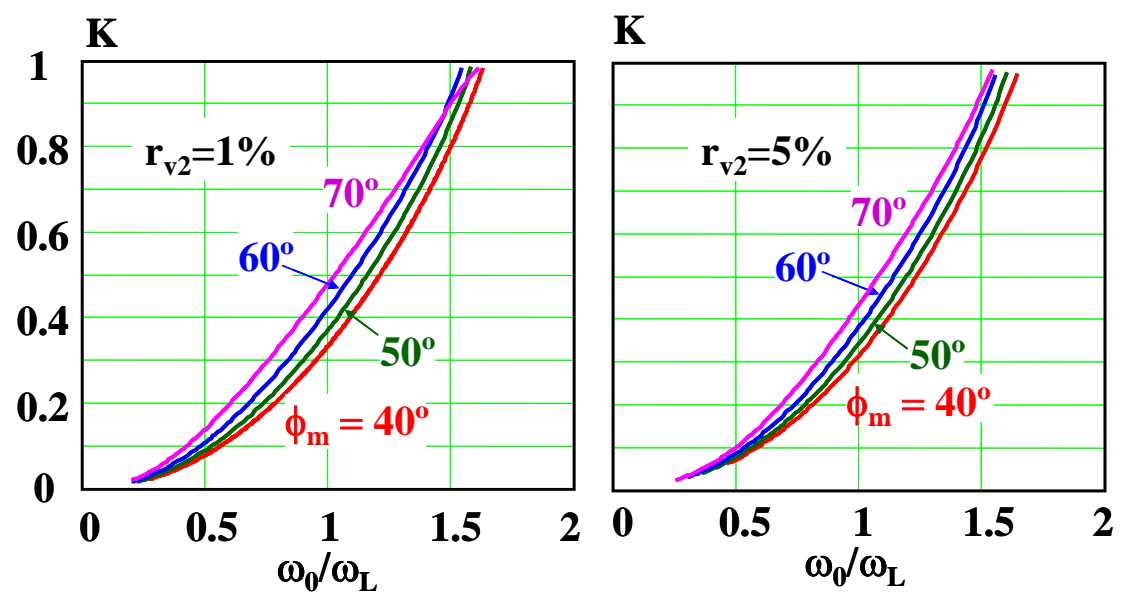

(a)
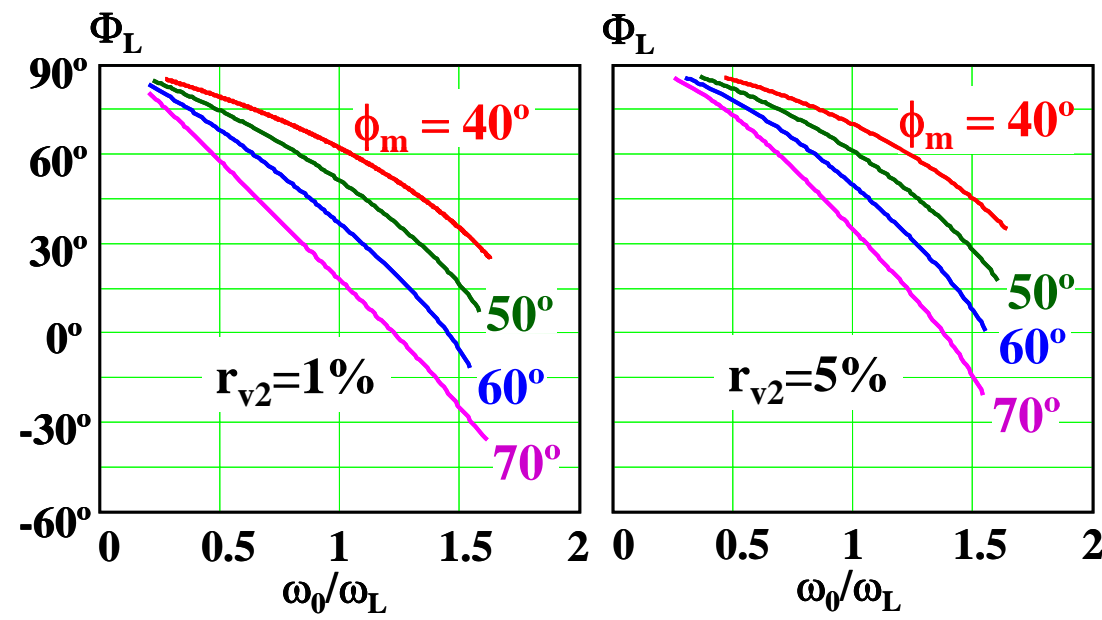

(b)

Fig. 9. Required values of K (a) and $\Phi_{\mathrm{L}}$ (b) as a function of the desired values of $\omega_{0} / \omega_{\mathrm{L}}$ and $\phi_{\mathrm{m}}$ for two different values of the output voltage ripple $r_{v 2}$. 
shown in Fig. 9 allow us to calculate the values of $\mathrm{K}$ and $\Phi_{\mathrm{L}}$ as a function of the desired feedback-loop crossover frequency and phase margin.

The normalized values of the error amplifier pole, $\omega_{\mathrm{Ap}} / \omega_{\mathrm{L}}$, and the dc gain, $\mathrm{A}_{\mathrm{Rm}}$, as a function of both the phase margin, $\phi_{\mathrm{m}}$, and of the normalized crossover frequency, $\omega_{0} / \omega_{\mathrm{L}}$, are given in Fig. 10. These plots allow us to calculate the compensator needed for the desired feedback-loop crossover frequency and phase margin.

Although we have already obtained the information to determine the compensator needed to guarantee a desired crossover frequency (i.e., a desired PFC bandwidth $\omega_{0}$ ) with a reasonable degree of stability (i.e., a desired $\phi_{\mathrm{m}}$ ), the design procedure is still not complete. This is because the line-current harmonic content corresponding to the values of $\mathrm{K}$ and $\Phi_{\mathrm{L}}$ obtained from Fig. 9 have not yet been checked. In fact this harmonic content should be low enough to guarantee either reasonable values of the Power Factor (PF) and of the Total Harmonic Distortion (THD) or compliance with any regulation regarding low-frequency line harmonics.
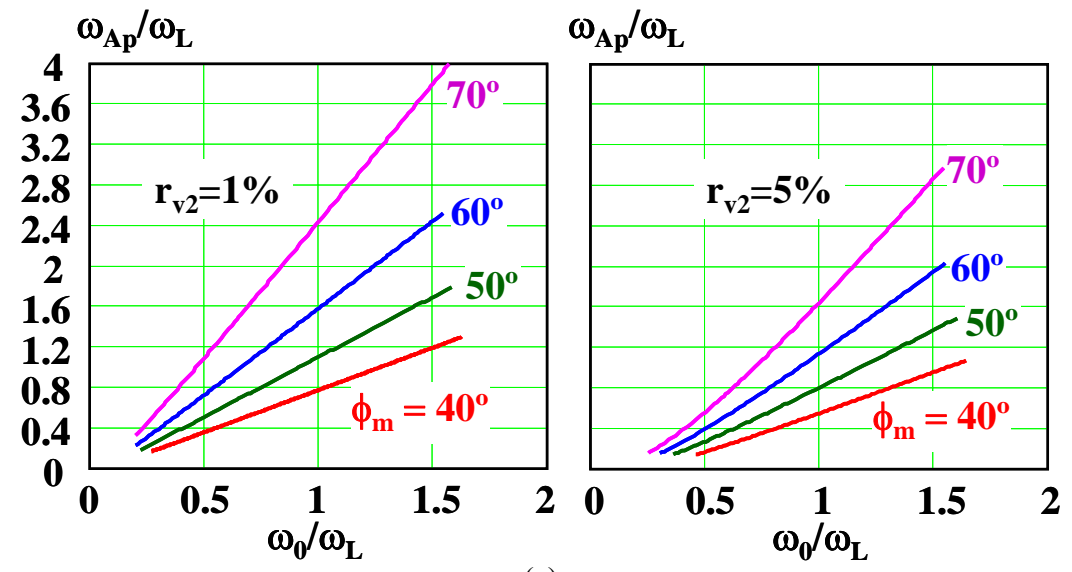

(a)
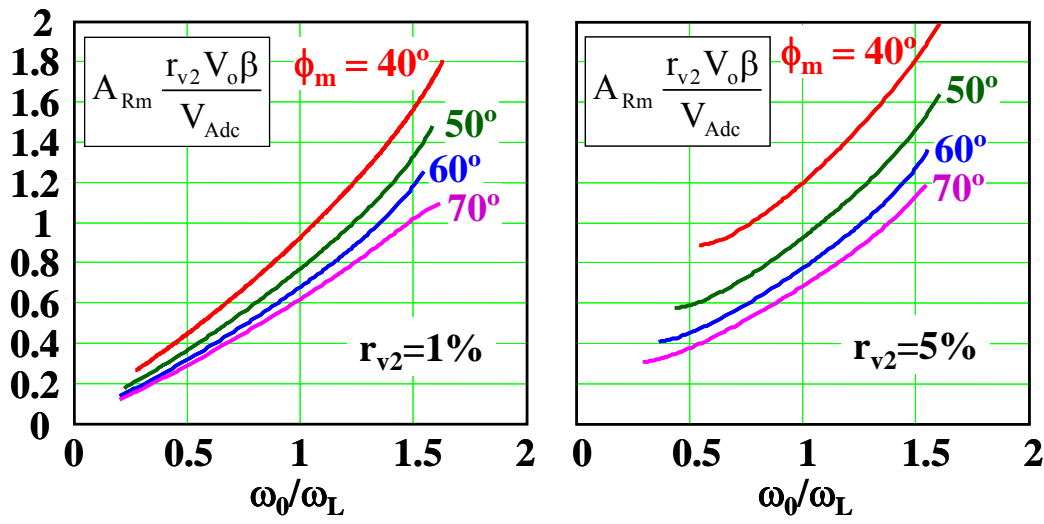

(b)

Fig. 10: $\omega_{A p} / \omega_{L}$ (a) and $A_{R m} \cdot r_{v 2} \cdot V_{o} \cdot \beta / V_{A d c}$ (b) as a function of $\omega_{0} / \omega_{L}$ and $\phi_{m}$ for two values of the output voltage ripple. 
The relationship between the control signal ripple (i.e., $\mathrm{K}$ and $\Phi_{\mathrm{L}}$ ) and the harmonic content (i.e., PF and THD) can be easily obtained from (19), (20), (21) and (28), especially bearing in mind that the only significant line harmonic is the third one:

$$
\begin{gathered}
\mathrm{THD}=\frac{\mathrm{I}_{\mathrm{gL} 3 \mathrm{p}}}{\mathrm{I}_{\mathrm{gL} 1 \mathrm{p}}}=\frac{\mathrm{K}}{\sqrt{4+\mathrm{K}^{2}+4 \mathrm{~K} \sin \Phi_{\mathrm{L}}}}, \\
\mathrm{PF}=\frac{\mathrm{P}_{\mathrm{gav}}}{\mathrm{I}_{\mathrm{gLrms}} \frac{\mathrm{V}_{\mathrm{gp}}}{\sqrt{2}}}=\frac{\sqrt{2}\left(1+0.5 \mathrm{~K} \sin \Phi_{\mathrm{L}}\right)}{\sqrt{2+\mathrm{K}^{2}+2 \mathrm{~K} \sin \Phi_{\mathrm{L}}}} .
\end{gathered}
$$

From the relationships shown in Fig. 9 between the control signal ripple (i.e., $\mathrm{K}$ and $\Phi_{\mathrm{L}}$ ) and the feedback-loop behaviour (i.e., $\omega_{0} / \omega_{\mathrm{L}}$ and $\left.\phi_{\mathrm{m}}\right)$ and from (56) and (57), we can easily obtain the plots shown in Fig. 11, where the PF and THD are given as functions of the behaviour of the feedback loop.

Although knowledge of the values of PF and THD as functions of the desired $\omega_{0} / \omega_{\mathrm{L}}$ and $\phi_{\mathrm{m}}$ values is very interesting, it is of
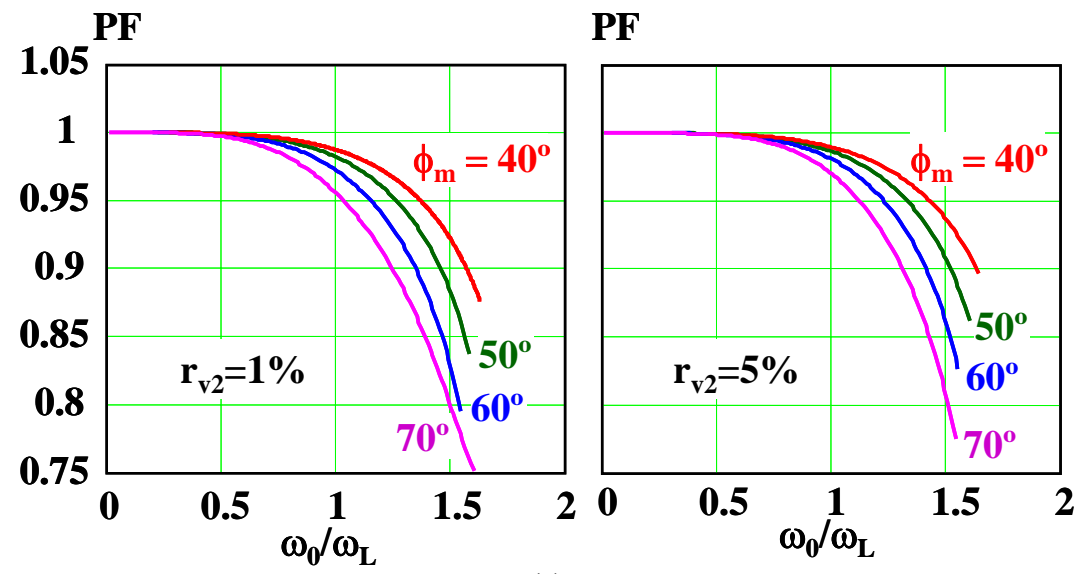

(a)

\section{THD [\%]}

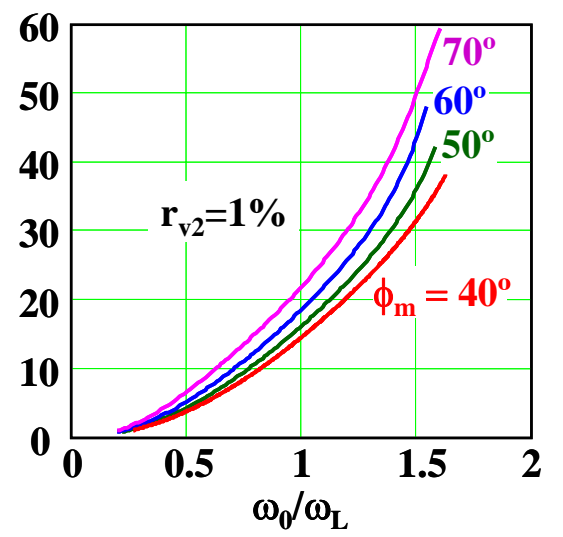

THD [\%]

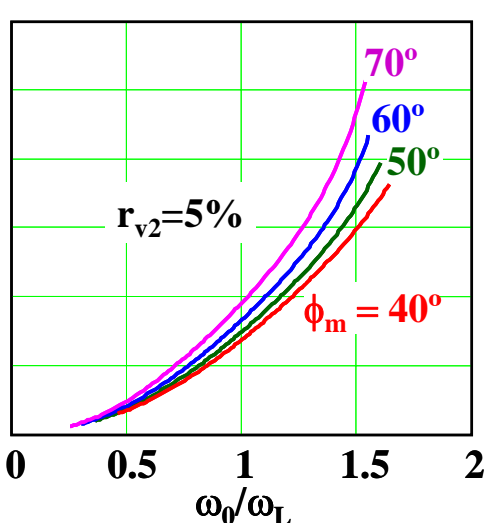

(b)

Fig. 11: PF (a) and THD (b) as a function of $\omega_{0} / \omega_{\mathrm{L}}$ and $\phi_{\mathrm{m}}$ for two values of the output voltage ripple. 
greater interest to establish the relationships between these desired feedback-loop values and current regulations regarding the harmonic content in the line, i.e., EN 61000-3-2 regulations [23, 24].

\section{COMPLying With EN 61000-3-2 REgUlations}

As is very well known, any piece of equipment can be classified into four classes according to EN 61000-3-2 regulations:

\section{Class A}

For equipment classified as belonging to Class A, the limit for the third harmonic is $2.3 \mathrm{~A}$ rms when the line voltage is $230 \mathrm{~V}$ rms. Note that this limit is an absolute value and does not depend on the power handled by the piece of equipment. The peak value of the third harmonic (the only significant line harmonic when there is ripple of twice the line frequency on the control signal $\mathrm{v}_{\mathrm{A}}$ ) is given by (20). Taking into account (28), this equation can be rewritten as follows:

$$
I_{g L 3 p}=\frac{2 P_{g a v}}{V_{g p}} \cdot \frac{K}{\left(2+K \sin \Phi_{L}\right)}
$$

The maximum power compatible with the regulations for Class A can be easily calculated by substituting the peak values of aforementioned rms current and voltage values (2.3 A rms and $230 \mathrm{~V} \mathrm{rms)} \mathrm{in} \mathrm{(58):}$

$$
\mathrm{P}_{\mathrm{g} \max _{-} \mathrm{A}}=529 \frac{\left(2+\mathrm{K} \sin \Phi_{\mathrm{L}}\right)}{\mathrm{K}} .
$$

The plot given in Fig. 12.a was obtained from the relationships between the control signal ripple (i.e., $\mathrm{K}$ and $\Phi_{\mathrm{L}}$ ) and feedbackloop behaviour (i.e., $\omega_{0} / \omega_{\mathrm{L}}$ and $\phi_{\mathrm{m}}$ ). As this figure shows, a PFC classified as Class A can process up to about $1 \mathrm{~kW}$ with a crossover frequency of $75 \mathrm{~Hz}$ (European line) or $90 \mathrm{~Hz}$ (American line) and with a phase margin of around $60^{\circ}$. This power increases to more than $2.5 \mathrm{~kW}$ if the crossover frequency coincides with the line frequency (i.e., $50 \mathrm{~Hz}$ in the case of the European line or $60 \mathrm{~Hz}$ in the American case).

\section{Class B}

In this case, the limits for each harmonic are also absolute values, which means that they do not depend on the power processed by the PFC. The only difference in relation to Class A is that these limits are slightly higher. Thus, the limit for the third harmonic is $3.45 \mathrm{~A}$ rms when the line voltage is $230 \mathrm{~V}$ rms. The maximum power compatible with EN 61000-3-2 in Class B equipment can be easily calculated by following the same procedure as for Class A: 


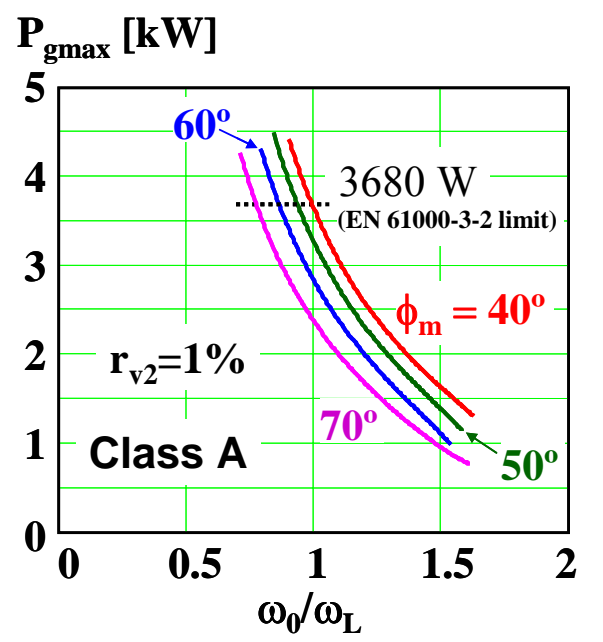

$\mathbf{P}_{\text {gmax }}[\mathrm{kW}]$

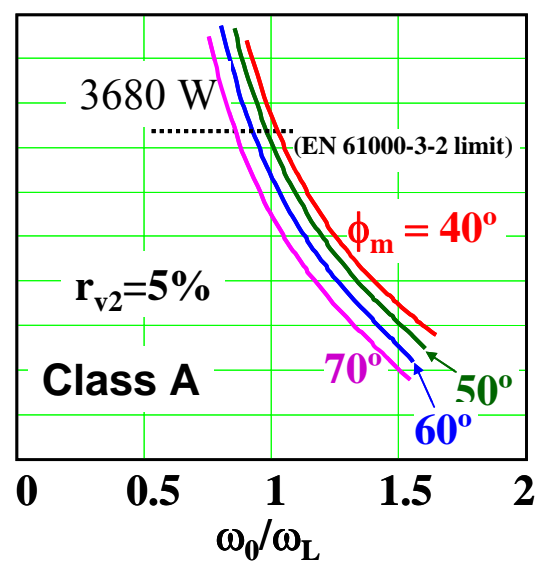

(a)
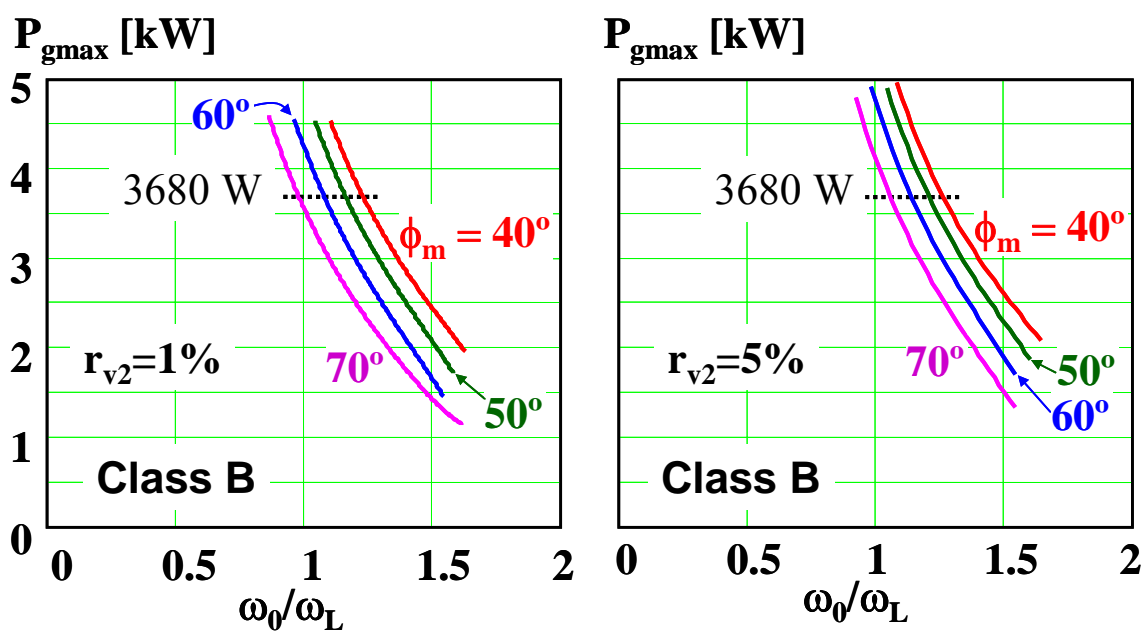

(b)

Fig. 12: $\mathrm{P}_{\text {gmax }}$ versus $\omega_{0} / \omega_{\mathrm{L}}$ and $\phi_{\mathrm{m}}$ for Class A (a) and for Class B (b) equipment for two values of the output voltage ripple.

$$
\mathrm{P}_{\mathrm{g} \max _{-} \mathrm{B}}=793,5 \frac{\left(2+\mathrm{K} \sin \Phi_{\mathrm{L}}\right)}{\mathrm{K}} .
$$

The relationships between the control signal ripple and feedback-loop behaviour leads to the plot given in Fig. 12.b. In this case, the PFC can process up to about $1.5 \mathrm{~kW}$ with a crossover frequency of $75 \mathrm{~Hz}$ (European line frequency) or $90 \mathrm{~Hz}$ (American line frequency), with a phase margin of $60^{\circ}$. This power increases to more than $3.6 \mathrm{~kW}$ when the crossover frequency coincides with the line frequency and the phase margin is likewise $60^{\circ}$.

\section{Class C}

In this class, the limit imposed on the rms value of the third harmonic depends on the PF and on the rms value of the first harmonic as follows: 


$$
\frac{\mathrm{I}_{\mathrm{gL} 3 \mathrm{p}}}{\sqrt{2}} \leq 0.3 \mathrm{PF} \frac{\mathrm{I}_{\mathrm{gL} 1 \mathrm{p}}}{\sqrt{2}}
$$

After substituting (19), (20) and (57) in (61), we obtain:

$$
0.212 \geq \frac{\mathrm{K} \sqrt{2+\mathrm{K}^{2}+2 \mathrm{~K} \sin \Phi_{\mathrm{L}}}}{\left(2+\mathrm{K} \sin \Phi_{\mathrm{L}}\right) \sqrt{4+\mathrm{K}^{2}+4 \mathrm{~K} \sin \Phi_{\mathrm{L}}}} .
$$

The relationships between the control signal ripple and the behaviour of the feedback loop leads to the plot given in Fig. 13. As this figure shows, compliance in Class $\mathrm{C}$ equipment is slightly more difficult. Thus, if a phase margin of around $60^{\circ}$ is desired, then the maximum crossover frequency is about $62 \mathrm{~Hz}$ (European line) or $74 \mathrm{~Hz}$ (American line), regardless of the power processed by the PFC.

\section{Class D}

As regards Class D equipment, compliance is not possible only when $-\pi / 2<\Phi_{\mathrm{L}}<-\pi / 4$ and $1>\mathrm{K}>0.878$ at the same time [21]. As this set of values of $\Phi_{\mathrm{L}}$ and $\mathrm{K}$ is not attainable using a standard compensator, compliance is thus always guaranteed.

\section{DESIGN EXAMPLES}

To illustrate the use of the plots given in Fig. 9-13 for the design of fast-response PFCs, several design examples are presented in this section.

\section{Design Example 1}

Design a PFC with $r_{v 2}=1 \%, \phi_{m}=70^{\circ}, P F \geq 0.9, T H D \leq 20$ and an overall bandwidth as high as possible. In this case the more

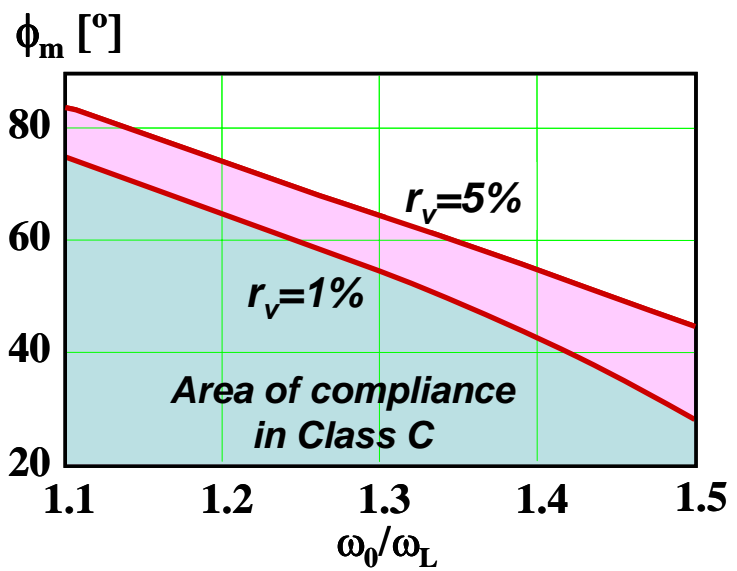

Fig. 13: Values of $\phi_{\mathrm{m}}$ and $\omega_{0} / \omega_{\mathrm{L}}$ that comply for Class C equipment. 
restrictive case is THD $\leq 20$, which corresponds to $\omega_{0} / \omega_{\mathrm{L}}=0.95$ (see Fig 11.b) instead of the case of PF $\geq 0.9$, which corresponds to $\omega_{0} / \omega_{\mathrm{L}}=1.24$ (see Fig. 11.a). Therefore, the maximum bandwidth attainable in these conditions is $\omega_{0}=0.95 \omega_{\mathrm{L}}$, which means 47.5 Hz in the case of the European line and $57 \mathrm{~Hz}$ in the case of the American line. Also from Fig. 11.a, the value of the PF is 0.963. According to Fig. 10.a, the value $\omega_{\mathrm{Ap}} / \omega_{\mathrm{L}}$ corresponding to $\omega_{0} / \omega_{\mathrm{L}}=0.95$ is $\omega_{\mathrm{Ap}} / \omega_{\mathrm{L}}=2.3$, which means that the pole of the compensator $A_{R}$ must be placed at $115 \mathrm{~Hz}$ (for the European line) and at $138 \mathrm{~Hz}$ (for the American line). The value of the product $A_{R m} \cdot r_{v 2} \cdot V_{o} \cdot \beta / V_{A d c}$ can be directly obtained from Fig. 10.b $\left(A_{R m} \cdot r_{v 2} \cdot V_{o} \cdot \beta / V_{A d c}=0.59\right)$, thus allowing the calculation of $A_{R m}$. The values of $\mathrm{K}$ and $\Phi_{\mathrm{L}}$ are easily determined from the plots shown in Fig. $9\left(\mathrm{~K}=0.44\right.$ and $\left.\Phi_{\mathrm{L}}=21.6^{\circ}\right)$. Moreover, if the PFC is used in a piece of equipment classified as Class A, the maximum power processed by the PFC compatible with the regulations will be $\mathrm{P}_{\text {gmax }}=2.59 \mathrm{~kW}$ (from Fig. 12.a), whereas if it is classified as Class B, this maximum power will be determined by the limit of application of the EN 61000-3-2 regulation (i.e., $3.68 \mathrm{~kW}$ ). The obtained values of $\mathrm{K}$ and $\Phi_{\mathrm{L}}$ satisfy (62) (i.e., $0.212>0.147$ ), which means that this PFC also complies with the regulations for Class C. Of course, it also complies in the case of Class D equipment, like any PFC with the standard proposed compensator. Finally, the main waveforms (for the design in the case of Class A) and the Bode plots of the overall feedback loop are given in Fig. 14.a.

\section{Design Example 2}

Design a $1.5 \mathrm{~kW}$, Class A PFC with $r_{v 2}=5 \%, \phi_{m}=60^{\circ}$ and an overall bandwidth as high as possible. In this case, the value of $\omega_{0} / \omega_{\mathrm{L}}$ can be obtained from Fig. 12.a $\left(\omega_{0} / \omega_{\mathrm{L}}=1.42\right)$, which means that the bandwidth is $71 \mathrm{~Hz}$ (European Line) or $85.2 \mathrm{~Hz}$ (American Line). The PF and THD values are 0.898 and $33.4 \%$, respectively (from Fig. 11). The compensator parameters obtained from Fig. 10 are $\omega_{\mathrm{Ap}}=1.81 \omega_{\mathrm{L}}(90.5 \mathrm{~Hz}$ for the European line and $108.6 \mathrm{~Hz}$ for the American line $)$ and $\mathrm{A}_{\mathrm{Rm}}=$ $1.17 \mathrm{~V}_{\mathrm{Adc}} /\left(\mathrm{r}_{\mathrm{v} 2} \cdot \mathrm{V}_{\mathrm{o}} \cdot \beta\right)$. Finally, the values of $\mathrm{K}$ and $\Phi_{\mathrm{L}}$ obtained from Fig. 9 are 0.78 and $16.2^{\circ}$, respectively. The obtained values of $\mathrm{K}$ and $\Phi_{\mathrm{L}}$ do not satisfy (62) (i.e., $0.212<0.263$ ), which means that this PFC does not comply with the regulations for Class $\mathrm{C}$ equipment. Finally, the main waveforms and the Bode plots of the overall feedback loop are given in Fig. 14.b.

\section{Design Example 3}

Design a $2 \mathrm{~kW}$, Class A PFC with $r_{v 2}=1 \%, \phi_{m}=70^{\circ}$, overall bandwidth as high as possible and taking into account the fact that the maximum value of $\mathrm{K}$ is limited to 0.4 due of the actual characteristics of the controller used. In this case, the more restrictive limit is the one imposed on $\mathrm{K}$ (which implies $\omega_{0} / \omega_{\mathrm{L}}=0.89$, Fig 9.a), since the limit imposed by the power processed by the PFC leads to a higher value of $\omega_{0} / \omega_{\mathrm{L}}\left(\omega_{0} / \omega_{\mathrm{L}}=1.09\right.$, from Fig 12.a). Therefore, the maximum bandwidth attainable in these conditions is $\omega_{0}=0.89 \omega_{\mathrm{L}}$, which means $44.65 \mathrm{~Hz}$ in the case of the European line and $53.58 \mathrm{~Hz}$ in the case of the American line. From Fig. 
11.a, the value of the PF is 0.971 , whereas the THD is $18.2 \%$ (Fig. 11.b). The compensator parameters obtained from Fig. 10 are $\omega_{\mathrm{Ap}}=2.15 \omega_{\mathrm{L}}$ (which means $107.5 \mathrm{~Hz}$ for the European line and $129 \mathrm{~Hz}$ for the American line) and $\mathrm{A}_{\mathrm{Rm}}=0.547 \mathrm{~V}_{\mathrm{Adc}} /\left(\mathrm{r}_{\mathrm{v} 2} \cdot \mathrm{V}_{\mathrm{o}} \cdot \beta\right)$. The values of $\Phi_{\mathrm{L}}$ obtained from Fig. 9 is $25.9^{\circ}$. The maximum power that the PFC could process that is compatible with the regulations would be $\mathrm{P}_{\text {gmax }}=2.875 \mathrm{~kW}$ (from Fig. 12.a), which is higher than the actual converter power. Finally, the main waveforms and the Bode plots of the overall feedback loop are given in Fig. 14.c.

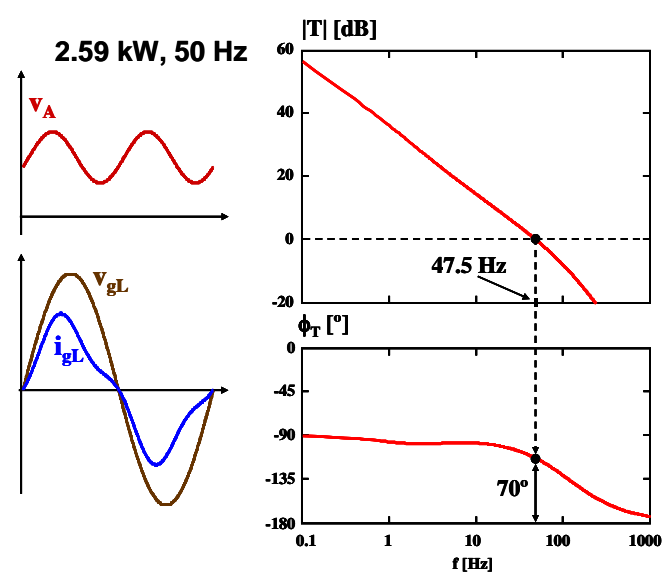

(a)
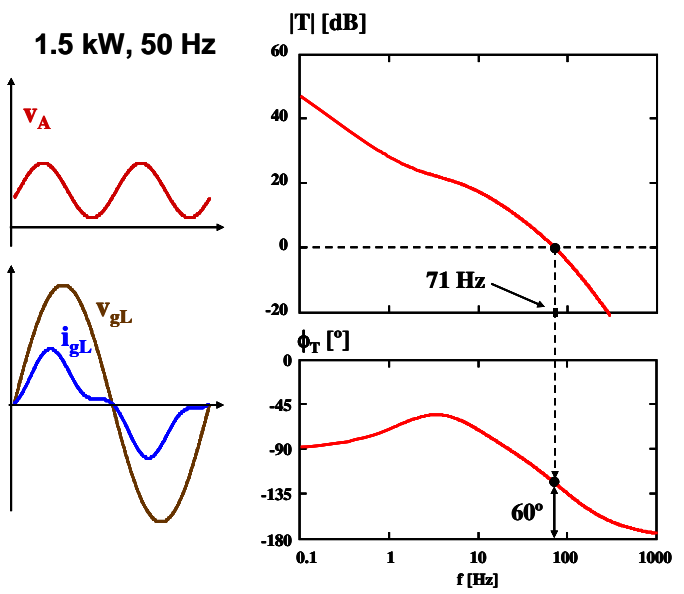

(b)
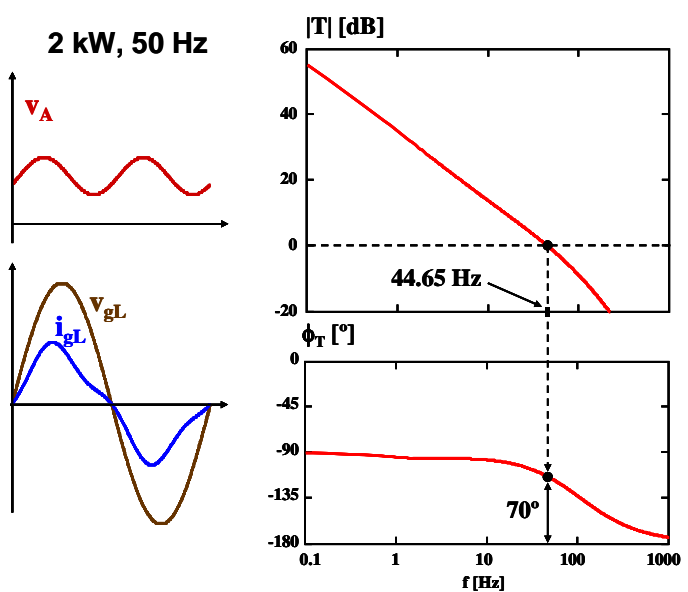

(c)

Fig. 14: Main waveforms (left) and Bode plots of the overall feedback loop (right) for the different design examples: a) Design Example 1. b) Design Example 2. c) Design Example 3. 


\section{Design Example 4}

Design a 500kW Boost PFC, Universal line voltage, $400 \mathrm{~V}$ output voltage, compliance with the EN 61000-3-2 regulations in the four classes, with $\mathrm{r}_{\mathrm{v} 2}=1 \%, \phi_{\mathrm{m}}=60^{\circ}$, overall bandwidth as high as possible and taking into account the fact that the maximum value of $\mathrm{K}$ is limited to 0.75 due of the actual characteristics of the controller used. In this case, the more restrictive limit is the one imposed by Class $\mathrm{C}$ of the regulations $\left(\omega_{0} / \omega_{\mathrm{L}}=1.24\right.$, from Fig 13$)$, since the limit imposed on $\mathrm{K}$ leads to a higher value of $\omega_{0} / \omega_{\mathrm{L}}$ $\left(\omega_{0} / \omega_{\mathrm{L}}=1.36\right.$, from Fig 9.a). A ratio of 1.2 is finally chosen for $\omega_{0} / \omega_{\mathrm{L}}$ (to have a security margin), which means that the maximum bandwidth attainable is $60 \mathrm{~Hz}$, corresponding to the case of operating from the European line, which is the worst case. The compensator parameters obtained from Fig. 10 are, approximately, $\omega_{\mathrm{Ap}}=2 \omega_{\mathrm{L}}$ (which means $\left.100 \mathrm{~Hz}\right)$ and $\mathrm{A}_{\mathrm{Rm}}=$ $0.851 \mathrm{~V}_{\text {Add }}\left(\mathrm{r}_{\mathrm{v} 2} \cdot \mathrm{V}_{\mathrm{o}} \cdot \beta\right)$. The values of $\mathrm{K}$ and $\Phi_{\mathrm{L}}$ obtained from Fig. 9.a and Fig. 9.b are about 0.6 and $20^{\circ}$, respectively. This design example was chosen to build the prototype used to obtain the experimental results.

\section{EXPERIMENTAL AND SIMULATED RESUlts}

Both experimental and simulated results of a PFC with an appreciable transient response were obtained from a prototype of a Boost PFC. The main specifications of this converter are the following:

- Input voltage: $85-265 \mathrm{~V}$.

- Input power: $500 \mathrm{~W}$.

- Output voltage: $400 \mathrm{~V}$.

- Relative ripple: $1 \%$, approximately.

- Switching frequency: $100 \mathrm{kHz}$.

- Power MOSFET: SPW47N60C3 (Infineon)

- Power diode: STTA2006 (ST).

- Controller: UC3854B (Texas Instruments)

- Main inductor: $329 \mu \mathrm{H}, 35$ turns, Molybdenum Permalloy Powder core (Arnold, $\mu_{\mathrm{r}}=125, \mathrm{OD}=1.84$ in).

Figure 15 shows the experimental results corresponding to a load step (1/3 to 1 ) obtained in closed-loop operation and when the line voltage is $230 \mathrm{~V}$. As this figure shows, the average value of the output voltage fits the theoretical value very well. It should be noted that the PFC reaches the steady-state in about $10 \mathrm{~ms}$ and the overshoot is about $15 \%$, which fits the values expected for these quantities from the values of $\omega_{0} / \omega_{\mathrm{L}}$ and $\phi_{\mathrm{m}}$. The line current and its harmonics (also when the line voltage is $230 \mathrm{~V}$ ) are 


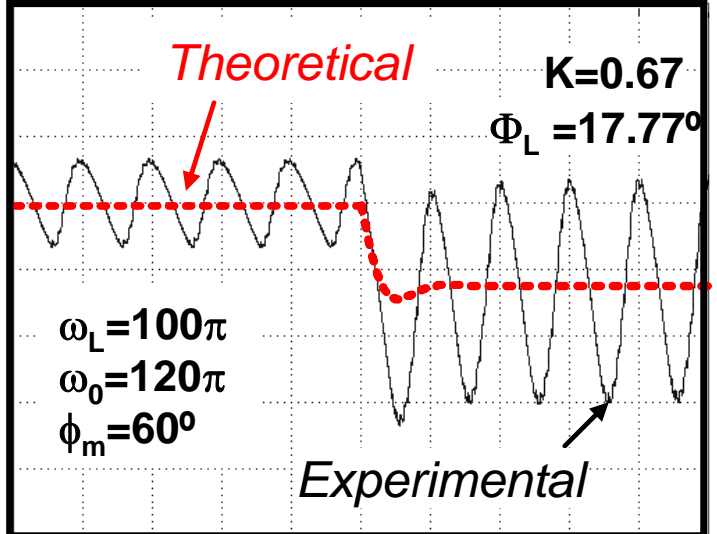

Fig. 15: Output voltage evolution after a load step which increases the output current threefold.

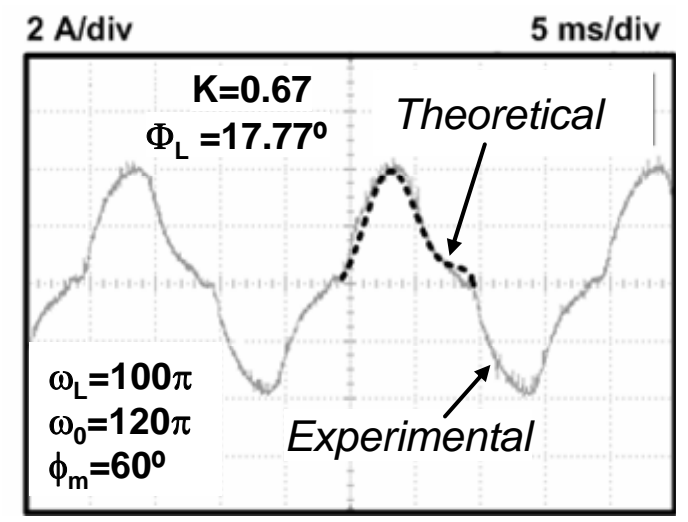

Fig. 16: Line current at full load.

given in Fig. 16 and in Fig. 17, respectively. As can be seen from the latter figure, the line harmonics are always below the limits imposed by EN 61000-3-2 for the four Classes. Due to the fact that $\omega_{0} / \omega_{\mathrm{L}}=1.2$ and $\phi_{\mathrm{m}}=60^{\circ}$, the harmonic content is near the limit imposed by the regulations for Class C equipment (see Fig. 13 and Fig. 17). Finally, some simulated results obtained using PSPICE are shown in Fig. 18, where they are compared with the results obtained according to the model developed in [22] and used here to close the output-voltage feedback loop. The simulated circuit is the one used in [21] for the same purpose. Each waveform was obtained for a specific value of $\omega_{0} / \omega_{\mathrm{L}}, \phi_{\mathrm{m}}$ and $\mathrm{r}_{\mathrm{v} 2}$ and always when the line voltage is $230 \mathrm{~V}$. Also in these cases, the simulated and the predicted results fit very well.

\section{CONCLUSIONS}

When a PFC is designed with a relatively-wide bandwidth compensator in the output-voltage feedback loop, its behaviour is different to that obtained with a narrow-bandwidth compensator. This is because of the influence of the voltage ripple that is present on the control signal. The design of the PFC output-voltage feedback loop determines its final dynamic behaviour, which 


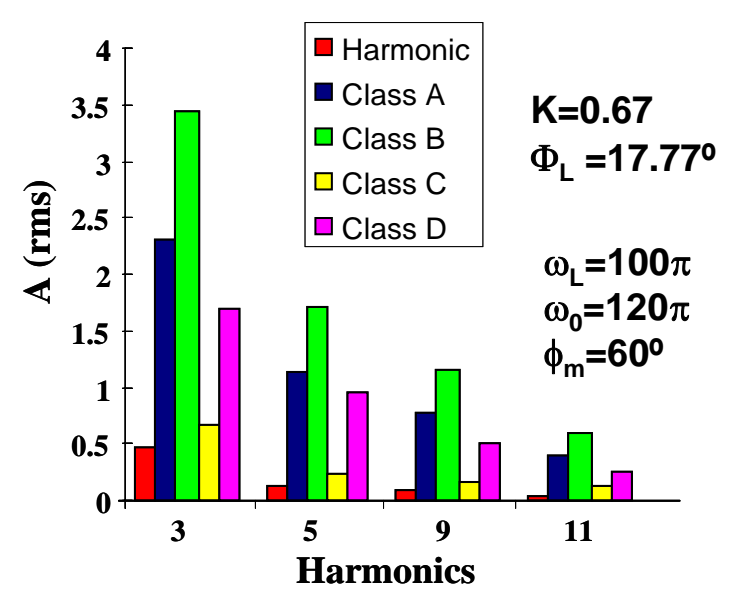

Fig. 17: Main line harmonics and the limits in all classes.

can be optimized to achieve the maximum bandwidth compatible with compliance with existing regulations regarding the injection of line harmonics and with converter stability. The design of this feedback loop has been approached in this paper. The results obtained show that the maximum crossover frequency attainable by a PFC with a standard compensator and compatible with a reasonable value of the phase margin (around $60^{\circ}$ ) is about 1.5 times the line frequency (i.e., $75 \mathrm{~Hz}$ in the case of the European line frequency and $90 \mathrm{~Hz}$ in the American case). This is also the actual limit for Class D equipment (power $<600 \mathrm{~W}$ ). For Class A and Class B equipment, the maximum crossover frequency (for a given phase margin) depends on the power processed by the PFC (see Fig. 12). However, the actual maximum crossover frequency attainable in Class $C$ equipment does not depend on the power and is lower than that corresponding to Classes A, B and D. It is thus about 1.25 times the line frequency for a phase margin of $60^{\circ}$, as Fig. 13 shows. Finally, the design procedure presented in this paper has been verified by both simulation and experimental results.

\section{ACKNOWLEDGMENT}

This work has been supported by the Spanish Ministry of Education and Science under Project TEC2007-66917/MIC and Grant AP2008-03380.

\section{REFERENCES}

[1] M. J. Kocher and R. L. Steigerwald, "An ac-to-dc converter with high quality input waveforms", IEEE Transactions on Industry Applications, vol. 19, no. 4, 1983, pp. 586-599.

[2] L. H. Dixon, "High power factor preregulators for off-line power supplies", Unitrode Power Supply Design seminar, 1990, pp I2-1 to I2-16.

[3] G. Spiazzi, P. Mattavelli, and L. Rossetto, "Methods to improve dynamic response of power-factor preregulators: an overview", $6^{\text {th }}$ European Conference on Power Electronics and Applications, 1995, pp. 3.754-3.759. 


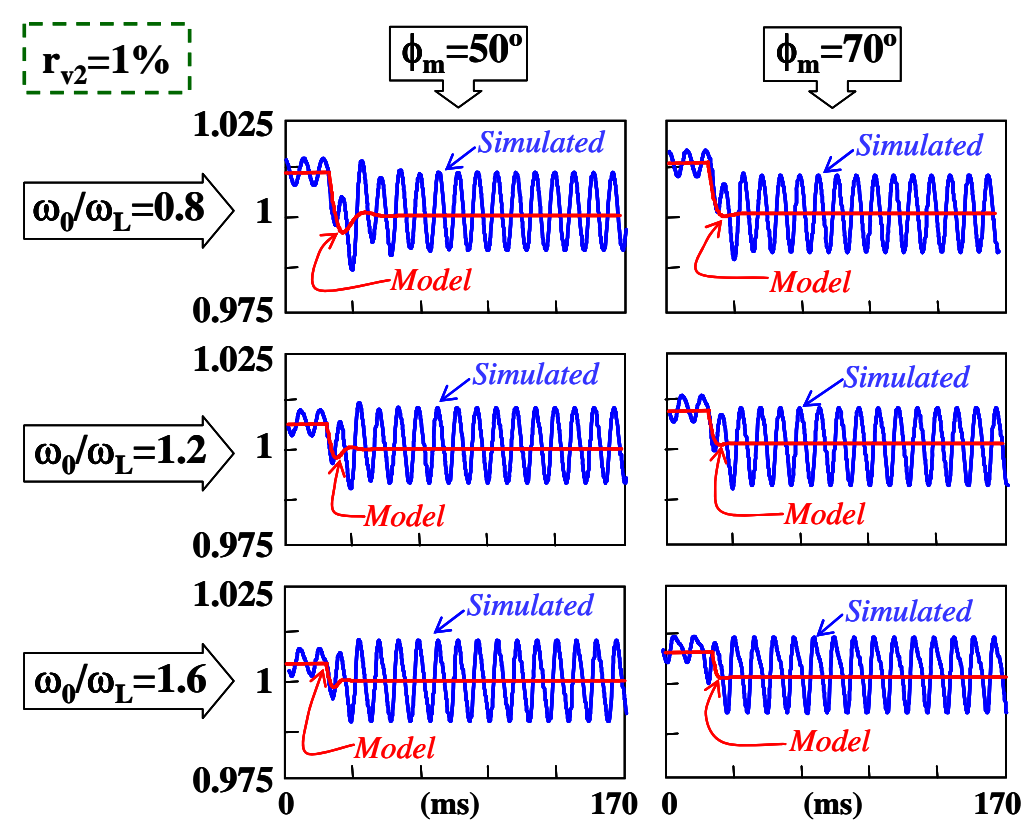

Fig. 18: Simulated and modelled values of the normalized output voltage after a load step (from $167 \mathrm{~W}$ to $500 \mathrm{~W}$ ). These results were obtained for different values of $\omega_{0} / \omega_{\mathrm{L}}$ and $\phi_{\mathrm{m}}$. However, $\mathrm{r}_{\mathrm{v} 2}=1 \%$ in all the simulations.

[4] S. Buso, P. Mattavelli, L. Rossetto and G. Spiazzi, "Simple digital control improving dynamic performance of power factor preregulators", IEEE Transactions on Power Electronics, vol. 13, no.5, September 1998, pp. 814-823.

[5] Z. Yang and P. C. Sen, "A novel technique to achieve unity power factor and fast transient response in ac-to-dc converters", IEEE Transactions on Power Electronics, vol. 16, no. 6, November 2001, pp. 764-775.

[6] A. Prodic, J. Chen, D. Maksimovic and R. W. Erickson, "Self-tuning digitally controlled low-harmonic rectifier having fast dynamic response", IEEE Transactions on Power Electronics”, vol. 18, no. 1, January 2003, pp. 420-428.

[7] P. Mattavelli, G. Spiazzi and P. Tenti, "Predictive digital control of power factor preregulators with input voltage estimation using disturbance observers ”, IEEE Transactions on Power Electronics, vol. 20, no. 1, January 2005, pp. 140-147.

[8] E. Figueres, J. M. Benavent, G. Garcerá and M. Pascual, "Robust control of power-factor-correction rectifiers with fast dynamic response”, IEEE Transactions on Industrial Electronics, vol. 52, no. 1, February 2005, pp. 66-76.

[9] A. Prodic, "Compensator design and stability assessment for fast voltage loops of power factor correction rectifiers", IEEE Transactions on Power Electronics, vol. 22, no.5, September 2007, pp.1719-1730.

[10] D. G. Lamar, A. Fernández, M. Arias, M. Rodríguez, J. Sebastián and M. M. Hernando, “A unity power factor correction preregulator with fast dynamic response based on a low-cost microcontroller", IEEE Transactions on Power Electronics, vol. 23, no. 2, March 2008, pp. 635-642.

[11] R. Ghosh and G. Narayanan, "A simple method to improve the dynamic response of single-phase PWM rectifiers", IEEE Transactions on Industrial Electronics, vol. 55, no. 10, October 2008, pp. 3627-3633.

[12] A. Fernández, J. Sebastián, P. J. Villegas, M. M. Hernando and D. G. Lamar, "Dynamic limits of a power-factor preregulator", IEEE Transactions on Industrial Electronics, vol. 52, no. 1, February 2005, pp.77-86. 
[13] F. Tsai, P. Markowski and E. Whitcomb, "Off-line flyback converter with input harmonic current correction", IEEE International Telecommunications Energy Conference, 1996, pp.120-124.

[14] M. Qiu, G. Moschopoulos, H. Pinheiro and P. Jain "Analysis and design of a single stage power factor corrected full-bridge converter", IEEE Applied Power Electronics Conference and Exposition, 1999, pp.119-125.

[15] L. Huber and M. Jovanovic, "Single-stage, single-switch, isolated power supply technique with input-current shaping and fast output-voltage regulation for universal input-voltage-range applications", IEEE Applied Power Electronics Conference and Exposition, 1997, pp.272-280.

[16] L. Huber and M. Jovanovic, "Design optimization of single-stage, single-switch input-current shapers", IEEE Transactions on Power Electronics, vol. 15, no. 1, January 2000, pp. 174-184.

[17] J. Sebastián, M. M. Hernando, A. Fernández, P. Villegas and J. Díaz, "Input current shaper based on the series connection of a voltage source and a loss-free resistor”, IEEE Transactions on Industry Applications, March/April 2001, pp.583-591.

[18] J. Sebastián, A. Fernández, P. Villegas, M. M. Hernando and J. M. Lopera, "A new Active Input Current Shaper for converters with symmetrically driven transformer", IEEE Transactions on Industry Applications, March/April 2001, pp.592600 .

[19] C. Qiao and K. M. Smedley, "A topology survey of single-stage power factor corrector with a boost type input-currentshaper", IEEE Transactions on Power Electronics, vol. 16, no. 3, May 2001, pp. 360-368.

[20] L. Huber, J. Zhang, M. M. Jovanovic and, F. C. Lee, "General topologies of single-stage input-current shaping circuits", IEEE Transactions on Power Electronics, vol. 16, no. 4, July 2001, pp. 508-513.

[21] J. Sebastián, D. G. Lamar, M. M. Hernando, A. Rodríguez and A. Fernández and "Steady-state analysis and modelling of power factor correctors with appreciable voltage ripple in the output-voltage feedback loop to achieve fast transient response", IEEE Transactions on Power Electronics, vol. 24, no. 11, November 2009 (in press right now).

[22] J. Sebastián, D. G. Lamar, M. M. Hernando, M. Rodríguez and A. Fernández, “Average small-signal modelling of the power stage of power factor correctors with a fast output-voltage feedback loop", IEEE Applied Power Electronics Conference and Exposition, 2009, pp. 998-1004.

[23] Electromagnetic compatibility (EMC)-part 3: Limits-section 2: Limits for harmonic current emissions (equipment input current<16A per phase), IEC1000-3-2 Document, 1995.

[24] Draft of the proposed CLC Common Modification to IEC 61000-3-2 Ed. 2.0:2000, October 2000.

[25]. R. B. Ridley, “Average small-signal analysis of the boost power factor corrector circuit”, VPEC Seminar Proceedings 1989, pp. 108-120. 